\title{
Plasmategnologie: 'n Kort oorsig oor die ontstaan, teorie en ' $n$ aantal toepassings daarvan
}

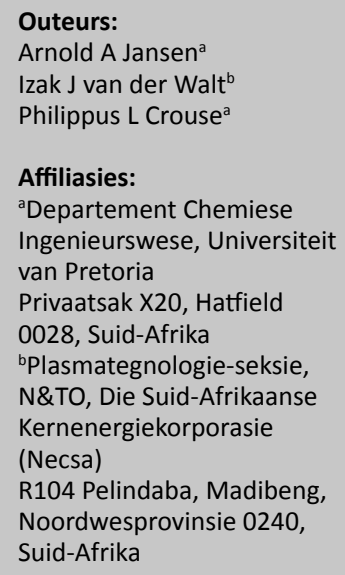

Korresponderende outeur: Arnold Jansen

E-pos:

aaj421216@gmail.com

Datums:

Ontvang: $\quad 14 / 10 / 19$

Aanvaar: $\quad 27 / 02 / 20$

Gepubliseer: 03/04/20

Hoe om hierdie artikel aan te haal:

Arnold A Jansen, Izak J van der Walt, Philippus L Crouse, Plasmategnologie: 'n Kort oorsig oor die ontstaan, teorie en ' $n$ aantal toepassings daarvan, Suid-Afrikaanse Tydskrif vir Natuurwetenskap en Tegnologie 39(1) (2020). https://doi.org/10.36303/ SATNT.2020.39.1.746

\section{Kopiereg:}

(c) 2020. Authors. Licensee: Die SuidAfrikaanse Akademie vir Wetenskap en Kuns. Hierdie werk is onder die Creative Commons Attribution License gelisensieer.
Daar word na plasmas as die vierde toestand van materie verwys. In die natuur manifesteer plasmas as korona-ontladings, weerlig, aurora borealis en in sterre soos die son. Plasmas kan ook opgewek word met elektriese boogontladings, radiofrekwensie-induksie, mikrogolwe, diëlektriese ontladings en lasers.

Die ontstaansgeskiedenis van mensgemaakte plasmas en meegaande elektrotegnologie sedert die middel van die $17^{\text {de }}$ eeu word in hierdie oorsigartikel opgesom. Die plasmatoestand word bespreek aan die hand van 'n algemene beskrywing en die fisiese eienskappe van 'n paar algemeen-gebruikte plasmagasse word ingesluit. 'n Aantal verskillende tipes plasmas en toepassings word kortliks bespreek, met die klem op termiese plasmas.

Suid-Afrikaanse navorsing en ontwikkeling op die gebied van plasmategnologie, hoofsaaklik by Mintek, internasionaal bekend op die gebied van pirometallurgie, en Necsa, word bespreek. 'n Kort oorsig van die Suid-Afrikaanse pirometallurgiese bedryf word ingesluit.

Spesiale fokus word geplaas op termiese afvalprosessering en plasmagesteunde vergassing word met konvensionele prosesse vergelyk. Plasmagesteunde vergassing vir energieproduksie word in meer besonderhede bespreek. Laastens word 'n blik gegee op die huidige internasionale plasmategnologieverskaffers

Sleutelwoorde: Plasma; oordragboog; nie-oordragboog; vergassing; afvalvernietiging; energieproduksie

Plasma technology: A brief overview of the origin, theory and a number of applications thereof: Plasmas are referred to as the fourth state of matter. In nature plasmas manifest as corona discharges, lightning, aurora borealis and stars such as the sun. Plasmas can also be generated by electrical arc discharges, radiofrequency induction, microwaves, dielectric barrier discharges and lasers.

The historic development of man-made plasmas and the associated electrical technology since the middle of the $17^{\text {th }}$ century is summarised in this review. The plasma state is discussed in general and the physical properties of a number of generally used plasma gases are included. A number of different plasmas and their applications are briefly discussed, with the emphasis on thermal plasmas.

Plasma-technological research and development in South Africa, mainly at Mintek in the field of pyrometallurgy, and Necsa, are discussed. A brief overview of the South African pyrometallurgical industry is provided.

Special attention is given to thermal waste processing and plasma-assisted gasification is compared to conventional processes. Plasma-assisted gasification for energy production is discussed in more detail. Lastly an overview is given of present international plasmatechnology suppliers.

Key words: plasma; transfer arch; non-transfer arch; gasification; waste disposal; energy production

\section{Inleiding}

'n Paar bekende voorbeelde van plasmaverskynsels in die natuur is sterre, weerligstrale, en die aurora verskynsels naby die pole. Irving Langmuir het die term "plasma" in 1928 begin gebruik om hierdie sg. vierde toestand van materie te beskryf (Langmuir, 1928).

Alhoewel plasmategnologie buite die vaktegnologiese veld minder bekend mag wees, is dit oor die afgelope sowat 200 jaar ontwikkel tot toepassings in vele aspekte van moderne 
tegnologie. Dink maar aan mikro-elektronika vir rekenaars, TV's, selfone en radio's, buisligte, chemiese analises, metallurgiese prosesse, afvalbehandeling en die groot droom van benutting van vrygestelde bindingsenergie in 'n kernversmeltingsreaktor.

Hierdie dokument bied 'n kort oorsig oor die ontstaansgeskiedenis van plasmategnologie, die aard van die plasmatoestand, 'n aantal toepassings daarvan en SuidAfrikaanse aktiwiteite in hierdie veld. Die gebruik van termiese plasmas in die herwinning van energie uit afval word in meer besonderhede bespreek as ' $n$ moontlike oplossing vir die omgewingsprobleme wat deur die moderne leefstyl veroorsaak word.

Ter afsluiting word inligting verskaf van 'n aantal internasionale verskaffers van plasmatoerusting en plasmaondersteunde prosesse vir energie-uit-afval toepassings soos uit verskeie bronne opgesom.

\section{Geskiedenis van plasmategnologie}

Daar word vir meer as 200 jaar reeds navorsing en ontwikkeling op plasmas en hul toepassings gedoen met die ontwikkeling van elektrotegnologie as een van die belangrike tegnologiedrywers, soos hieronder kortliks opgesom (Feinman, 1987a), (Reid, 1987):

- 1663 - von Guericke bou die eerste elektrostatiese opwekker (Kersten, 2019);

- 1671 - von Leibnitz maak vonkontladings met von Guericke se masjien (Kersten, 2019);

- 1803 - Petrov neem 'n kontinue boogontlading waar m.b.v. 'n battery met 4200 selle in serie (Kersten, 2019);

- 1807 - Davy bou 'n koolstofboogontladingslamp m.b.v. 'n 2000 sel battery (Brittanica, 2019);

- 1831 - Faraday ontdek elektromagnetiese induksie, ontwikkel die "Faraday skyf" of homopolêre gelykstroom-(GS)-kragopwekker (Page, 1958), (Mendenhall, 1956) en toon dat meganiese energie in elektrisiteit omgesit kan word. Moderne weergawes kan tot 2 Mega-ampère lewer;

- 1854 - Siemens berei osoon deur middel van 'n hoogspanningglimontlading in 'n lugstroom (Kersten, 2019);

- 1862 - Berthelot produseer asetileen met waterstof in 'n koolstofboogontlading (Doremus, 1907), (Berthelot, 1860);

- 1867 - Die eerste dinamo word onafhanklik ontwikkel deur Wheatstone, von Siemens en Varley (Deutsches Museum, 2019), (de Cew, 1882). Hiermee was die opwekking van plasmas nou nie meer afhanklik van batterye nie;

- 1878/9 - Siemens ontwikkel die GS boog-oond vir metallurgiese toepassings (Jones, 2014);

- 1891 - Tesla patenteer die "Teslaspoel", 'n hoëfrekwensietransformator wat korona-ontladings kan opwek (Kersten, 2019), waarmee o.a. ionisasie in plasmas geïnisieer kan word;
- 1897 - Moissan publiseer sy klassieke reeks eksperimente oor toepassing van plasmas in metallurgie en hoëtemperatuurchemie (Moissan, 1897). Hy berei die metale en karbiede van $\mathrm{Cr}, \mathrm{Mn}, \mathrm{Mo}, \mathrm{W}, \mathrm{U}$, $\mathrm{Zr}$, Ti, Si, $\mathrm{Al}$, en Ca. Hy isoleer $\mathrm{F}_{2}$ (1886), en ontvang die Nobelprys in 1906;

- 1900 - Héroult patenteer 'n wisselstroom (WS) boog-oond wat uiteindelik die oorheersende tegnologie vir staalvervaardiging sou word (Caron), (Stansfield, 1907) (Jones, 2014);

- 1903 - Die Birkeland-Eyde proses fikseer stikstof as die oksiede uit lug m.b.v. 'n wisselstroomboog in 'n magneetveld, vir die vervaardiging van salpetersuur (OxfordReference, 2018), (Maslan, 1969);

- 1907 - Schönherr ontwikkel 'n werwelgestabiliseerde GS-boog vir die fiksering van stikstof uit lug (Feinman, 1987a);

- 1920 - Saha publiseer sy vergelyking wat die verband tussen die ionisasievlak in 'n gas, die druk en temperatuur toon (Saha, 1920);

- 1922 - Gerdien en Lotz ontwikkel 'n watergestabiliseerde boogontlading (stoomplasma) (Gerdien, 1922), (Gerdien, 1923), (Hrabovsky, 2009), wat o.a. gebruik word in plasmaspreiwerk op veral groot oppervlaktes;

- 1924 - Langmuir ontwikkel die Langmuir-sonde waarmee plasmaparameters gemeet kan word (Langmuir, 1924);

- 1928 - Langmuir stel die term "plasma" voor vir die vierde toestand van materie (Langmuir, 1928) terwyl hy vir GEC werk (1909 - 1957). Hy ontvang die Nobelprys vir Chemie in 1932;

- 1934 - Mintek ontstaan uit samewerking tussen die Suid-Afrikaanse Departement van Mynwese en die Universiteit van die Witwatersrand vir die ontwikkeling van pirometallurgiese tegnologie (sien "Mintek" onder "Suid-Afrikaanse ontwikkeling" p. 11);

- 1938 - Chemische Werke Hüls begin grootskaalse vervaardiging van asetileen uit steenkool en waterstof met plasmabranders van tot $6 \mathrm{MW}$ en het in die 1980's 150 MW geïnstalleer gehad. USCO het in die 1970's 'n aanleg met 3x8 MW Hüls branders in Vanderbijlpark gehad vir direkte reduksie van yster (Barcza, 1986);

- 1950 - Maecker ontwikkel 'n gesegmenteerde plasmabrander en beskryf die Maecker- effek (Maecker, 1956);

- 1951 - Spitzer bou die "Stellarator" termokernversmeltingstoestel (Spitzer, 1958);

- 1957 - Gage patenteer die plasmasweis en -snyproses (Gage, 1957);

- 1958 - General Electric bemark die eerste tiristor (silikonbeheerde gelykrigter) (Burgess, 2011) wat uiteindelik diodes in gelykstroomkragbronne sou vervang en teen 1980 was tiristors met 'n vermoë van $5 \mathrm{kV} / 2 \mathrm{kA}$ al beskikbaar (Holtmann, 2019);

- 1958 - Sakharov, Tamm, en Artsimovich stel die eerste Tokamak kernversmeltingsreaktor bekend (Artsimovich, 1958); 
- 1960 - NASA ontwikkel in samewerking met Linde plasmabranders van tot $20 \mathrm{MW}$ vir windtonnels, om terugkeerkondisies vir ruimtetuie te simuleer (Camacho, 1988a). Soortgelyke werk is ook in Rusland uitgevoer;

- 1965-Die navorsingsgroep van die Paton Welding Institute (Russiese Akademie vir Wetenskap, Kiev), ontwikkel 'n oordragboogplasmabrander vir die vervaarding van vlekvrystaal (Feinman, 1987a). Plasmanavorsing by Baikov Institute of Metallurgy and MaterialsScience (Moskou), AlmaAta (Almaty) Research Institute for Experimental and Theoretical Physics en die Russian Academy of Science (Novosibirsk) sedert 1948;

- $\quad 1970$ - In Japan, Rusland, en die VSA is plasmabooghersmelting (0.1 - $1 \mathrm{MW}$ ) algemeen (Reid, 1987);

- 1976 tot 1986 - SKF Steel Engineering in Swede (ScanArc) begin ' $n$ program om betroubare, doeltreffende hoëkapasiteit-plasmabranders te ontwikkel as alternatief vir fossielbrandstof vir staalproduksie. Die program ontwikkel teen 1980 'n 10 MW plasmabrander gevolg deur 'n reeks plasma-aanlegte, bv vir herwinning van elektriese boogoondstof, allooi-elemente uit VVS boogoondstof en die produksie van ferrochroom. ScanArc Plasma Technologies AB ontstaan in 1989 uit hierdie werk en word vandag deur sy werknemers besit;

- 1992 - Bekendstelling van 'n 4.5 kV, 600 A, IGBT ("insulated-gate bipolar transistor") wat die bou van 'n nuwe geslag kompakte gelykstroomkragbronne moontlik maak.

Sedert die 1980's het plasmaprosessering in twee rigtings begin ontwikkel (Murphy, 2014), nl. die meer historiese gebruik van termiese plasmas (bv. in metallurgie, plasmasproeideponering, materiaalmodifisering, chemiese hoëtemperatuurprosesse, afvalvernietiging, analitiese chemie) en die gebruik van nie-ewewigsplasmas (bv. mikro-elektronika, oppervlakmodifisering, deklagies, analitiese chemie, mediese toepassings, ens).

\section{Die plasmatoestand Algemene beskrywing}

Die opsommende beskrywing van die plasmatoestand wat hier volg, is geneem uit verskeie standaardbronne' (Boulos, 1994c), (Zhukov, 2007b), (Feinman, 1987b). Daar word dikwels na 'n plasma as die vierde toestand van materie verwys. Kortliks bestaan plasmas uit neutrale en gelaaide spesies wat uit die aanvangsgas self gevorm word. Alhoewel dit die teenwoordigheid van ladings is wat tot plasmagedrag aanleiding gee, is die plasma as geheel neutraal. 'n Verskeidenheid van dissosiasie- en ionisasieprosesse gee aanleiding tot die vorming van neutrale en gelaaide molekule en atome in die teenwoordigheid van vry elektrone en fotone. Die tempo van dissosiase word onder gestadigde toestande gebalanseer deur die tempo van herkombinasie.
Energie-oorgange tussen gebonde toestande, vry-gebonde toestande, en vry-vry toestande, is gedeeltelik verantwoordelik vir die liguitstraling vanuit plasmas. Die energie in die plasma kan so hoog wees dat daar bykans geen neutrale spesies teenwoordig is nie en die plasma is dan ten volle geïoniseerd. Dit gebeur byvoorbeeld in'n argonplasma bo $20000 \mathrm{~K}$.

Oor die algemeen word daar onderskei tussen termiese (of ewewigs-) plasmas, en nie-termiese (of nie-ewewigs-) plasmas. Die temperatuur van vrybewegende partikels (atome, ione, radikale en neutrale molekule) word bepaal deur hul gemiddelde kinetiese energie volgens:

$$
\frac{3}{2} k T_{i}=\frac{1}{2} m_{i} \mathrm{v}_{\mathrm{rms}, \mathrm{i}}^{2}
$$

waar $k$ die Boltzmann-konstante is, en $T_{i}, m_{i}$ en $v_{i}$ onderskeidelik die temperatuur, massa en $v_{r m s, i}$ die wortel van die gemiddelde snelheidkwadraat van die $i^{\text {de }}$ partikelspesie aandui.

Vir tegnologiese toepassings word plasmas oor die algemeen deur die toepassing van 'n elektriese veld opgewek. Alle elektries gelaaide spesies word natuurlik deur hierdie veld versnel. Elektrone word egter a.g.v. hul lae massas (meer as $1000 \times$ kleiner as dié van protone) baie vinniger versnel en die energie wat deur ander spesies vanaf die veld verkry word, is weglaatbaar klein in vergelyking daarmee. Tydens plasma-aanvang word 'n klein aantal elektrone (geskep deur bv. 'n vonk of 'n Tesla-spoel) tot bo die ionisasiepotensiaal van die plasmagas versnel. Dit gee aanleiding tot ' $n$ kaskade van addisionele elektrone wat op hulle beurt weer tot bo die ionisasiepotensiaal versnel, totdat ' $n$ bestendige toestand bereik word waar die tempo van die ionisasieprosesse identies is aan die van die verskillende elektronverliesprosesse.

Die energieë van die ander spesies teenwoordig in die sisteem word deur botsings met die elektrone, botsings tussen spesies en absorpsie en emissie van fotone bepaal. Indien die botsingsfrekwensie hoog genoeg is, vind energieverdeling so effektief plaas dat slegs een temperatuur gebruik kan word om die kinetiese energie van al die spesies, asook die energieverdeling tussen interne energietoestande, te beskryf. Wanneer dit geld, word gesê dat die plasma botsings-gedomineerd is en in volledige termodinamiese ewewig verkeer. Onder bepaalde toestande kan tegnologiese plasmas so ' $n$ toestand in die praktyk benader en word gesê dat die plasma in lokale termodinamiese ewewig (LTE-ewewig) verkeer. Oor die algemeen is dit egter nie die geval nie. In die reël verskil die elektrontemperatuur van die ioontemperatuur en van die temperatuur afgelei vanaf interne kwantumoorgange.

Die teenoorgestelde van termiese ewewig kom voor in plasmas waar die botsingsfrekwensie laag is. Die plasma in die korona van die son, wat tydens volledige verduistering sigbaar is, is ' $n$ voorbeeld van so ' $n$ nie-termiese ewewig. 
Die elektrondigtheid in die korona is laag en die elektrontemperatuur baie hoog (van die orde $10^{6} \mathrm{~K}$ ), soos uit die spektraallyne van Fe afgelei kan word. Die optiese digtheid van die korona is baie laag, sodat die populasie van energievlakke deur straling geïgnoreer kan word. In die koronamodel word dus aanvaar dat opwaartse oorgange slegs deur elektron- of fotonbotsings geskied, terwyl depopulasie na gelang van kondisies in die plasma, hoofsaaklik deur straling (X-strale, UV en termiese straling), geskied (Aschwanden, 2004). Die ewewig wat so bereik word, staan as 'n korona-ewewig bekend. Die benaming "korona" verwys na 'n omringende gloed of stralekrans, en die gebruik van die term word nie tot die son beperk nie. 'n Korona kan ook rondom skerp voorwerpe in sterk elektriese velde waargeneem word, 'n plasmaverskynsel wat bekend staan as ' $n$ korona-ontlading, en waarvan die aard nie met die plasma in die korona van die son verwar moet word nie. Enkele toepassings van korona-ontladings word later bespreek.

Die kombinasie van elektriese veldsterke en druk bepaal watter tipe plasma-ewewigte in die praktyk sal manifesteer en die verband, $E / p$, word gebruik om die vereistes vir die elektriese veldsterkte $(E)$ en die druk $(p)$ op te som. By lae drukke en hoë veldsterkte is die botsingsfrekwensie laag, en die versnelling en dryftempo van elektrone hoog. Die elektrontemperatuur, $T_{e^{\prime}}$ gevolglik baie hoër as die swaarspesietemperatuur, waarna as die gastemperatuur, $T_{g^{\prime}}$, verwys sal word. By hierdie plasmas ( $E / p$ van die orde $\left.10^{5} \mathrm{~V} \mathrm{~m}^{-1} \mathrm{kPa}^{-1}\right)$ is die gastemperatuur gewoonlik na aan kamertemperatuur en word oor die algemeen daarna verwys as nie-termiese plasmas, "koue" plasmas of glimontladings. By hoër drukke is $T_{e} \approx T_{g}$ en 'n plasma wat in benaderde termiese en chemiese ewewig is, heers. Termiese-plasmas vorm wanneer $E / p$ van die orde $10^{-2}$ $\mathrm{V} \mathrm{m} \mathrm{m}^{-1} \mathrm{kPa}^{-1}$ is. In sulke plasmas word energie hoofsaaklik deur die swaar spesies (atome, ione, radikale en neutrale molekule) oorgedra en die temperatuur is tussen $1 \mathrm{eV}$ en $10 \mathrm{Ev}(1 \mathrm{eV} \approx 7740 \mathrm{~K})$.

Soos in Figuur 1 vir argon geïllustreer, verskil die temperature van elektrone $\left(\mathrm{T}_{\mathrm{e}}\right)$ en die gasspesies $\left(\mathrm{T}_{\mathrm{g}}\right)$ by lae

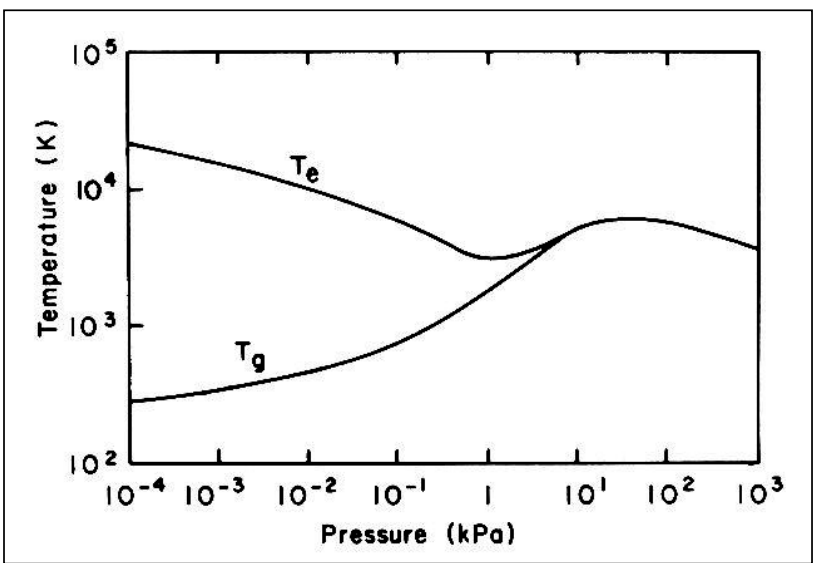

FIGUUR 1: Elektron- en gastemperatuur $(\mathrm{K})$ as funksie van absolute druk $(\mathrm{kPa})$ (Boulos, 1994b) drukke aansienlik, maar benader mekaar namate die druk in die stelsel styg.

By 'n druk van ongeveer $10 \mathrm{kPa}$ begin die plasma termiese (en ook chemiese) ewewig bereik en kan van 'n termiese plasma gepraat word. Die potensiaalverloop in 'n boogontlading toon groot gradiënte naby die elektrodes (die sg. anode- en katodeval) en 'n relatief lae gradiënt in die boog self (Boulos, 1994a). Die deursnit van die stroomdraende deel van die plasma toon ook variasie en insnoering kom veral in die katodegebied voor sodat radiale stroomkomponente daar ontstaan. In 'n boogplasma lei selfinteraksie van sulke stroomkomponente met die magneetveld van die plasmastroom tot plasmaversnelling in die rigting van wyer-wordende stroomkanaal. Snelhede van nagenoeg $100 \mathrm{~m} / \mathrm{s}$ kan bereik word vir stroomwaardes van $100 \mathrm{~A}$ of meer. Hierdie verskynsel staan as die Maeckereffek bekend (Maecker, 1956). Mintek in Suid-Afrika het 'n aansienlike hoeveelheid werk in hierdie verband gedoen vir die geval van gelykstroom-boogoonde. (Reynolds, 2004), (Reynolds, 2010).

In hoë-intensiteitontladings (I >10 A, p >10 kPa) neig die boogplasma na LT-ewewig. In plasmas by termiese ewewig kan groothede soos samestelling, warmtekapasiteit, warmtegeleidingsvermoë en entalpie met vrug gedefinieer word. Die verloop van hierdie groothede as funksie van temperatuur is sterk nie-lineêr. By poli-atomiese gasse is hierdie variasies meer belangrik en vind die nie-lineêre gedrag reeds by laer temperature plaas as by monoatomiese gasse.

\section{Plasmagasse}

Plasmas kan in enige gas opgewek word, maar vir termiese plasmas word in die nywerheid hoofsaaklik argon, stikstof, suurstof en lug gebruik. Die warmtekapasiteit van die plasmagas by konstante $\operatorname{druk}\left(C_{p}\right)$ is 'n belangrike parameter wanneer dit by keuse van toepassings kom. Die energieinhoud of entalpie $(H)$ van die gas by 'n bepaalde temperatuur $(T)$ word bereken uit die temperatuurintegraal van die warmtekapasiteit:

$$
H(T)=\int_{T_{v e r w}}^{T} C_{p}(T) d T
$$

Die krommes in Figuur 2 (a),(b) en Figuur 3(a),(b) soos bereken met TERRA sagteware (Trusov, 2006), toon duidelik die nie-lineêre gedrag van die warmtekapasiteit en entalpie van bogenoemde plasmagasse. Die sg. "bevrore" warmtekapasiteit is die som van die bydraes van al die spesies in die stelsel by 'n gegewe temperatuur.

Waterstof of helium word bv. as skutgas in radiofrekwensieplasmas gebruik vanweë hul hoë warmtekapasiteit, wat help om die hitte-oordrag na die wand van die toestel te beperk.

Sommige plasmatoestelle maak gebruik van gas met 'n besondere hoë massapesifieke entalpie. Die gasentalpie in 
Gerdien-Lotz stoomplasmas is byvoorbeeld sowat 'n ordegrootte hoër as vir 'n lugplasma by dieselfde temperatuur (Zhukov, 2007e) soos ook afgelei kan word uit Figuur 3 (a) vir bv. die temperatuurgebied $5000 \mathrm{~K}$ tot $10000 \mathrm{~K}$ en die verskil in warmtekapasiteite (Figuur 2(a)). Die hellingveranderinge in die gasentalpiekrommes in Figuur 3 (a) en (b) reflekteer die verloop van die dissosiasie en ionisasie van die plasmagasse. Die dissosiasie van meeratomige gasse tot mono-atomiese neutrale spesies in die gebied $3000 \mathrm{~K}$ tot $6000 \mathrm{~K}$ word gevolg deur ionisasie tussen $12000 \mathrm{~K}$ en $13000 \mathrm{~K}$ soos ook gesien kan word uit die verloop van die krommes in(a) en (b).
By'n gegewe temperatuur is die elektriese geleidingsvermoë $(\sigma)$ van $\mathrm{Ar}, \mathrm{H}_{2}, \mathrm{~N}_{2}$ en $\mathrm{O}_{2}$ bykans dieselfde aangesien hul ionisasiepotensiale nie veel verskil nie (tussen $13.6 \mathrm{eV}$ en $15.7 \mathrm{eV})$, terwyl dié van He veel hoër is $(24.6 \mathrm{eV})$ (Barbalace, 2019). Die gevolg hiervan is dat by atmosferiese druk en $10000 \mathrm{~K}$ genoemde gasse se geleidingsvermoë ongeveer $2000 A V^{-1} m^{-1}$ is, en dié van He by dieselfde temperatuur slegs ongeveer $500 A V^{-1} \mathrm{~m}^{-1}$ (Fauchais, 1987).

'n Lys van 'n paar algemene plasmagasse en gasmengsels vir vergassingstoepassings word in Tabel 1 getoon tesame met katodemateriale en voor- en nadele.

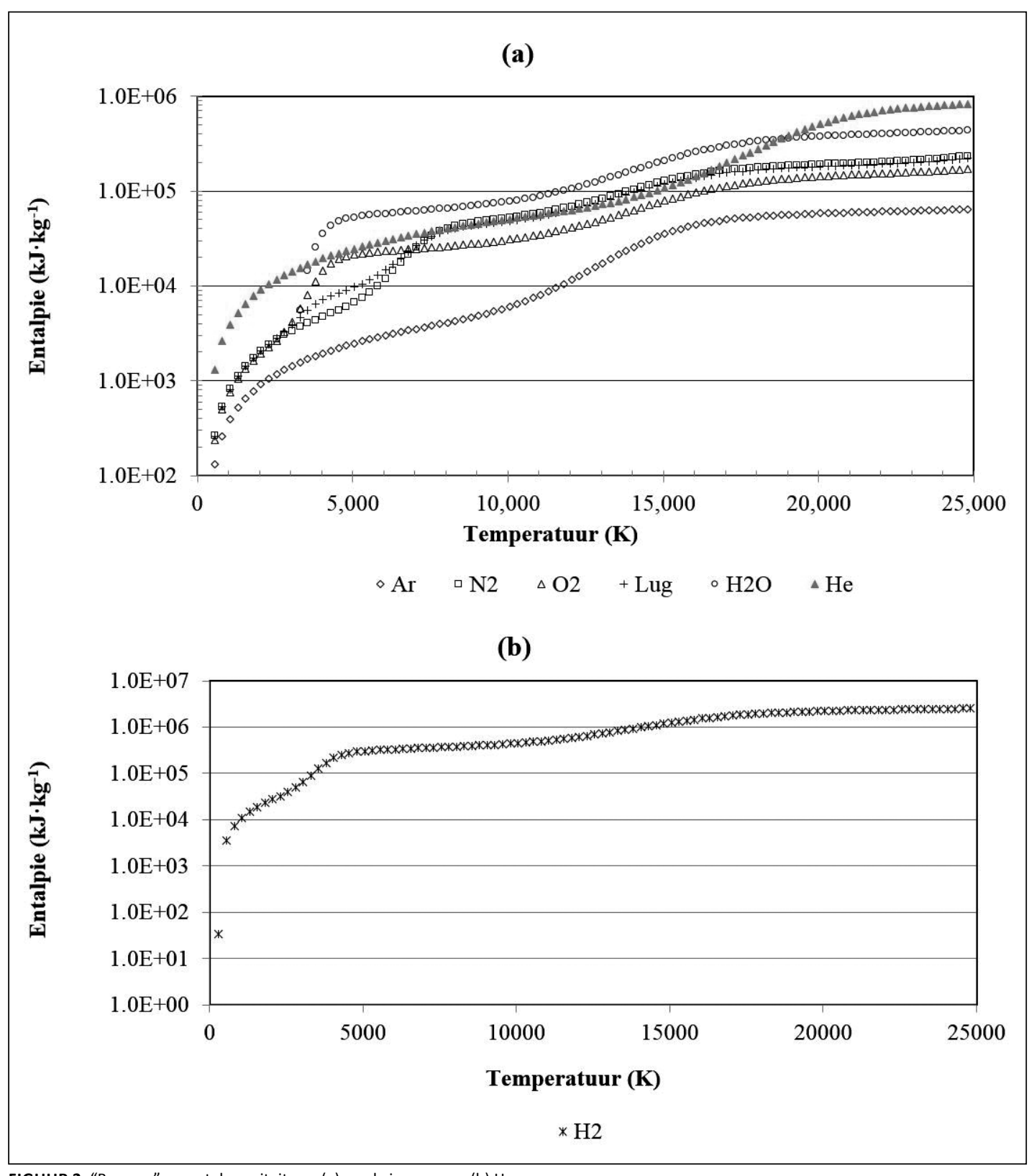

FIGUUR 2: "Bevrore" warmtekapasiteit van (a) verskeie gasse en (b) $\mathrm{H}_{2}$. 


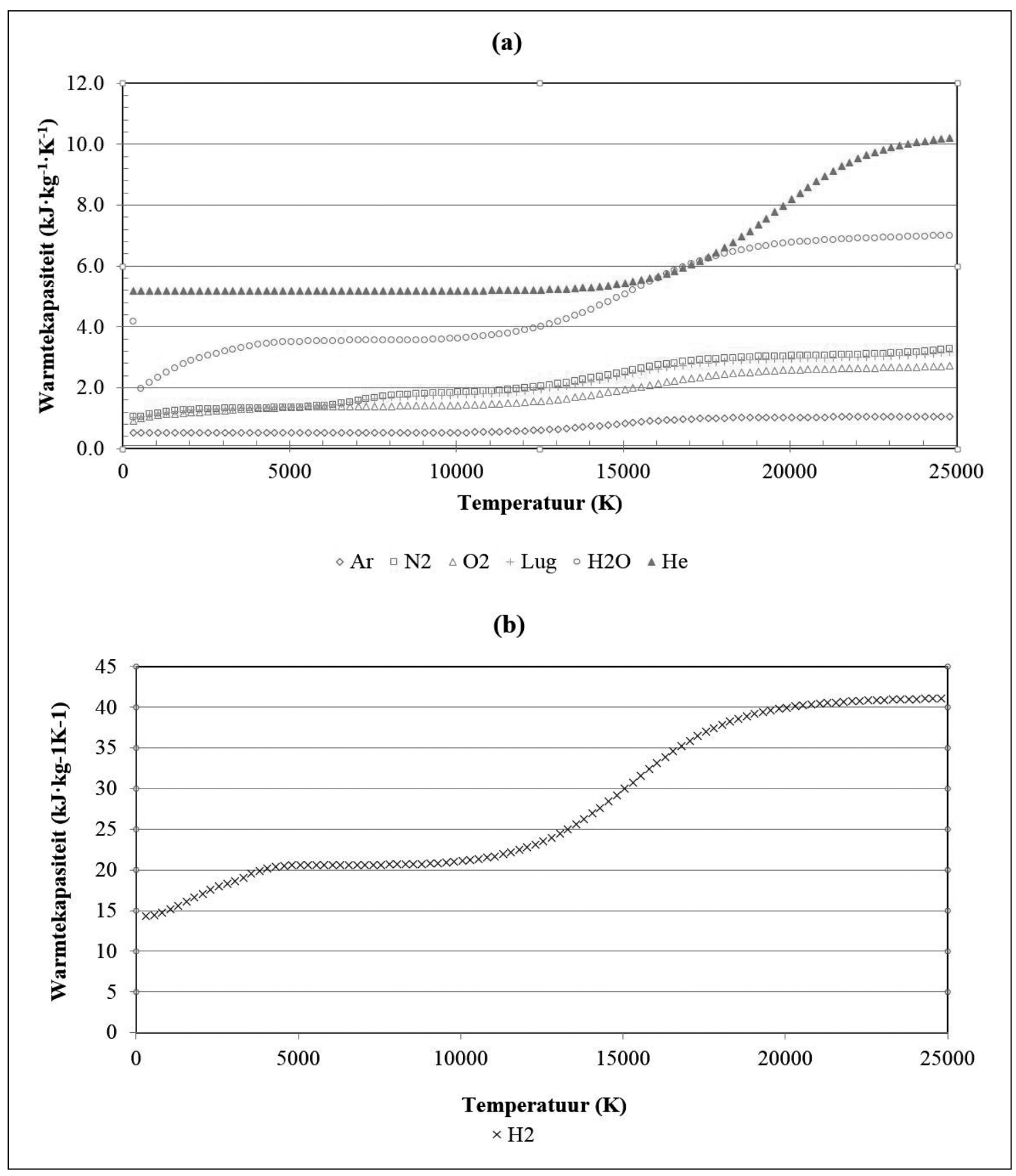

FIGUUR 3: Entalpie van (a) verskeie gasse en (b) $\mathrm{H}_{2}$ as funksie van temperatuur by atmosferiese druk.

Vir suurstof-bevattende plasmas kan die katode beskerm word deur 'n diafragma tussen die katode en anode te installeer en dan 'n inerte gas soos argon by die katode in te voer. Die plasmagas, bv. suurstof, word tussen die diafragma en anode ingevoer. Die aanvanklike boog ontstaan tussen die katode en diafragma en word dan deur eksterne skakeltuig oorgedra na die anode.

\section{Tipes plasmas}

Plasmas kan opgewek word deur elektriese ontladings, elektromagnetiese induksie, mikrogolwe en lasers. Die tipe plasma hang af van die druk in die stelsel soos in par. 1.1 aangetoon. Nie-termiese plasmas vorm by drukke laer as
$10 \mathrm{kPa}$ en kan opgewek word deur mikrogolwe (MG), radiofrekwensie-(RF)-velde of deur middel van elektrodes. Termiese plasmas vorm by drukke hoër as $10 \mathrm{kPa}$, maar word normaalweg na aan atmosferiese druk bedryf en kan opgewek word met GS- en WS-ontladings (50 tot $60 \mathrm{~Hz}$ ), radiofrekwensie (RF) of mikrogolwe (MG). Boogontladings wat tussen elektrodes gevorm word kan met GS en WS (50 tot $60 \mathrm{~Hz}$ ) bedryf word. By 'n oordragboog vorm die werkstuk die een elektrode, terwyl beide elektrodes in 'n nie-oordragboog plasmabrander ingebou is en die gasstroom 'n stertvlam uitblaas wat vir prosesseringsdoeleides aangewend kan word (vergelyk Figuur 4). 
TABEL 1: Plasmagas-opsies vir gebruik by vergassing

\begin{tabular}{|c|c|c|c|}
\hline Plasma gas & Katode-materiaal & Voordele & Nadele \\
\hline Stikstof & Wolfram/Torium & $\begin{array}{l}\text { Verlengde katode leeftyd. O2 toevoer word afsonderlik beheer. } \\
\text { Indien drukwisselabsorpsie (Eng.Pressure Swing Absorption (PSA)) } \\
\text { gebruik word, kan die uitskotgas (O2) as oksidant gebruik word, } \\
\text { afsonderlik beheer en toegevoer. Verminderde NOx vorming. } \\
\text { Optimum katodeleeftyd. }\end{array}$ & $\begin{array}{l}\text { Logistiek ( } \mathrm{LN}_{2} \text { of silinders) indien nie op terrein geproduseer } \\
\text { met drukwisselabsorpsie (DWA). Verdunning van produkgas } \\
\text { met N2 verlaag die verbrandingswarmte. }\end{array}$ \\
\hline Suurstof & $\begin{array}{l}\text { Sirkonium, } \\
\text { Hafnium }\end{array}$ & $\begin{array}{l}\text { Goeie beheer oor redokskondisies in die reaktor. Geen verdunning } \\
\text { van produkgas met inerte gasse. Lae NOx. }\end{array}$ & $\begin{array}{l}\text { Logistiek (LOx, of silinder kassette) indien nie op terrein } \\
\text { geproduseer met DWA. Verkorte katodeleeftyd. }\end{array}$ \\
\hline Lug & $\begin{array}{l}\text { Sirkonium, } \\
\text { Hafnium }\end{array}$ & Eenvoudige logistiek (plaaslike kompressor) & $\begin{array}{l}\text { Verdunning van produkgas met } \mathrm{N}_{2^{\prime}} \text { verlaag verbrandings- } \\
\text { warmte. Vorming van } \mathrm{NO}_{x} \text { in plasma. Verkorte katodeleeftyd. }\end{array}$ \\
\hline $\begin{array}{l}\text { Suurstof- } \\
\text { verrykte lug }\end{array}$ & $\begin{array}{l}\text { Sirkonium, } \\
\text { Hafnium }\end{array}$ & $\begin{array}{l}\text { Minder verdunning van produkgas met } \mathrm{N} 2 \text { as in die geval van lug. } \\
\text { Op terrein met drukwisselabsorpsie voorsien. Uitskotgas kan as } \\
\text { instrumentlug gebruik word. }\end{array}$ & $\begin{array}{l}\text { Matige verdunning van produkgas en afname in } \\
\text { verbrandingswaarde. } \mathrm{NO}_{\mathrm{x}} \text { vorming in plasma. Verkorte } \\
\text { katodeleeftyd. }\end{array}$ \\
\hline $\begin{array}{l}\mathrm{CO} / \mathrm{CO}_{2} \\
\text { Water en/of } \\
\text { stoom }\end{array}$ & Grafiet & $\begin{array}{l}\text { Goedkoop plasmagasse } \\
\text { Goedkoop plasmagas, baie hoë entalpie. } 100 \mathrm{~kW} \text { tot } 300 \mathrm{~kW} \text { GS } \\
\text { branders kommersieel beskikbaar }\end{array}$ & $\begin{array}{l}\text { Nog eksperimenteel* } \\
\text { Nog nie kommersieel toegepas in vergassingsproses nie }\end{array}$ \\
\hline
\end{tabular}

*(Mostaghimi, 2015).

\section{Korona-ontladings}

Die korona-ontladings waarna hier verwys word, is 'n plasmaverskynsel wat as ' $n$ violet-blou korona (liggloed) rondom voorwerpe in ' $n$ sterk elektriese veld manifesteer. Korona-ontladings kan beduidende verliese in transmissielyne veroorsaak en vind plaas wanneer die elektriese potensiaalgradient hoog genoeg is om ' $n$ korona van geïoniseerde lug daromheen te vorm ('n sg. Enkelelektrodeontlading), maar onvoldoende is om 'n vonkontlading (twee-elektrode-ontlading) na nabygeleë voorwerpe te veroorsaak. Korona-ontlading in lug lei tot die vorming van korrosiewe gasse soos osoon $\left(\mathrm{O}_{3}\right)$ en stikstofoksiede $\left(\mathrm{NO}_{\mathrm{x}}\right)$.

Beheerde korona-ontladings word ondermeer gebruik vir etsing van polimeeroppervlakke om kleefvermoë te bevorder (Ebnesajjad, 2014), dekontaminasie van biologiese en chemiese agente (Cormier, 2007) in fotokopieerders en in osoongenerators vir watersuiwering.

\section{Diëlektriesesperlaag-ontladings}

Diëlektriese-ontladingsplasmas is gepulseerde, nie-termiese, ontladings by atmosferiese druk wat, anders as korona-ontladings, geluidloos en ruimtelik bestendig voorkom (Brandenburg, 2017). Dit word gevorm tussen twee elektrodes wat deur ' $n$ diëlektriese materiaal geskei word en is reeds in 1857 gebruik vir osoonproduksie. Omdat die elektrodes deur ' $n$ baie dun diëlektriese medium geskei word, is die veldgradient reeds by relatief lae spanning genoegsaam om tot die ontlading aanleiding te gee. Die ontlading kan dus by laer aangewende spanning plaasvind as korona-ontladings en dit kan ook meer akkuraat tydens toepassings soortgelyk aan dié van koronaontladings aangewend word. Hedendaagse toepassings sluit in: oppervlakbehandeling; dekontaminasie van besoedelde gasstrome; die "pomp" van UV eksimeer gaslasers (Eliasson, 1988) wat o.a. gebruik word in mediese toepassings, bv. vir wondsterilisasie en die behandeling van huidinfeksies (Dyer, 2013), (Weltmann, 2016)

\section{Glimontladings}

Glimontladings kan opgewek word tussen elektrodes (buisligte), met behulp van elektrodelose induktiewe of kapasitiewe koppeling met radiofrekwente velde, of mikrogolwe. Dit word toegepas in die aanbring van deklagies soos diamantagtige koolstof (Crouse, 1993), verwydering van deklagies soos die TRISO-deklagies van korrelbedreaktorbrandstof (Van der Walt, 2011), skoonmaak/dekontaminasie van sensitiewe substrate en voorbehandeling van oppervlakke om die kleefvermoë van lak, verf of kleefmiddels te verbeter (Wolf, 2010).

\section{Laserplasmas}

Lasers word in die nywerheid algemeen gebruik vir presisie-uitsny- en sweiswerk.

Wanneer 'n baie kort puls van intense laserlig op 'n teiken gefokus word, en die drywing is hoog genoeg, kan materiaal verdamp en tot die plasmatoestand verhit word. Laser-geïnduseerde plasmas word met vrug aangewend vir spektroskopiese materiaalanalise (Thakur, 2007) en word onder andere ook gebruik om intense kort x-straal pulse op te wek in plasma-deeltjieversnellers (Nature.com, 2019) en as laser-ontstekers vir kernversmeltingsplasmas' (Basov, 1972), (Heller, 2019).

\section{Mikrogolfplasmas}

Mikrogolfplasmas word in die nywerheid algemeen bedryf by 'n frekwensie van $2.45 \mathrm{GHz}$. Mikrogolfplasmas by atmosferiese druk word byvoorbeeld gebruik vir die reiniging, sterilisasie en dekontaminasie van oppervlaktes (Leins, 2013), die voorbehandeling daarvan om die kleefvermoë van verf en kleefmiddels te verbeter en vir die deponering van deklagies (Kopecki, 2008). Klein mikrogolfplasmas kan ook gebruik word vir biomediese doeleindes en vir die behandeling van klein voorwerpe met komplekse geometrie. Groter, hoëtemperatuurplasmas kan gebruik word vir afgasreiniging, chemiese sintese en plasmasproeideponering. 


\section{Radiofrekwensieplasmas}

Radiofrekwensieplasmas word onder bepaalde kondisies opgewek deur induktiewe koppeling van die magnetiese veld, of kapasitiewe koppeling van die elektriese veld met 'n gas. Die aard van die plasma (termies of glimontlading) hang af van die plasmagas, die druk en die grootte van die geïnduseerde velde.

Kapasitief-gekoppelde plasmas vereis ' $n$ hoë kapasitansie tussen die RF-veld en die plasma en dus 'n hoë RFspanning. Induktief-gekoppelde plasmas vereis weer 'n hoë induktansie tussen die RF veld en die plasma en dus 'n hoë RF-stroom (Clarycon.com, 2019). 'n Breedvoerige beskrywing van induktief-gekoppelde plasmas is deur Boulos (Boulos, 1985) gepubliseer.

Induktief-gekoppelde plasmas word o.a. gebruik in induktiefgekoppelde-optiese-emissiespektroskopie ("IGP-OES") of as ioonbron in induktiefgekoppelde-massaspektrometrie ("IGP-MS"). By vonkbronmassaspektrometrie (Eng. spark source mass spectrometry, SSMS) word 'n RF-hoogspanningvonkontlading tussen twee elektrodes gebruik, waarvan een ' $n$ elektries-geleidende analitiese monster is, om 'n stroom ione vir analise op te wek (Smith, 2014).

Nywerheidstoepassings, waar kontaminasie deur elektrodemateriale vermy moet word, sluit onder andere halfgeleiervervaardiging (Okumura, 2010), die suiwering en sferoïdisering van keramiek- en metaalpoeiers (Boulos, 2004), (TEKNA, 2019a) en die aanspuit van metaal- en keramiekdeklagies (Fauchais, 2014,), (TEKNA, 2019b) in.

Radiofrekwente induksie word tans ondersoek vir die stabilisering van die plasma in tokamak versmeltingsreaktore (Reiman, 2018).

\section{Oordragboogplasmas}

Oordragboogplasmas word gevorm tussen 'n elektrode en die werkstuk as teen-elektrode bv. by sweis-, plasmasnywerk en in hoogoonde, soos in Figuur 4 vir 'n sweisboog aangetoon. Die energie-oordrag by oordragboogplasmas is hoog (tot $10^{7} \mathrm{Wm}^{-2}$ ) (Heberlein, 2009) en word aangevul deur Joule-verhitting van die werkstuk a.g.v. die elektriese stroom wat daardeur vloei.

Gelykstroom, enkelfase- en driefasewisselstroom kan gebruik word, met werkende elektrodes (katodes) van grafiet, Söderbergelektrodes of oordragboogplasmabranders. Die oordragboogplasmabranders kan van die warmkatode of holkatode tipe wees (Camacho, 1988b) en lg. kan ook in omgekeerde polariteit (as anodes) bedryf word (Camacho, 1987).

Die eerste kommersiële boogoond is in 1878 deur Siemens ontwikkel met gelykstroom en 'n grafietkatode en dit word in beginsel vandag nog gebruik (Jones, 2014). Oor die algemeen vind gelykstroom- en wisselstroomgedrewe oordragboogplasmas wye toepassing in die metallurgiese bedryf vir die produksie van metale, hersmelting van skroot en verhitting van smeltkroese vir kontinue gietwerk.

Vakuumbooghersmelting word gebruik vir die vervaardiging van baie suiwer metale soos bv. $\mathrm{Si}$, Ti, en $\mathrm{Zr}$ (Retech, 2019b).

Radio-aktiewe afval (Switserland (Zwilag, 2019), Boelgarye (WNN, 2018)), gevaarlike chemiese afval (Tetronics, 2019), (Retech, 2019a) en die as uit munisipale afvalverbranders word in plasmaprosesse verwerk en skadeloos gestel (Phoenix, 2019b)' (Fabry, 2013), (Heberlein, 2008).

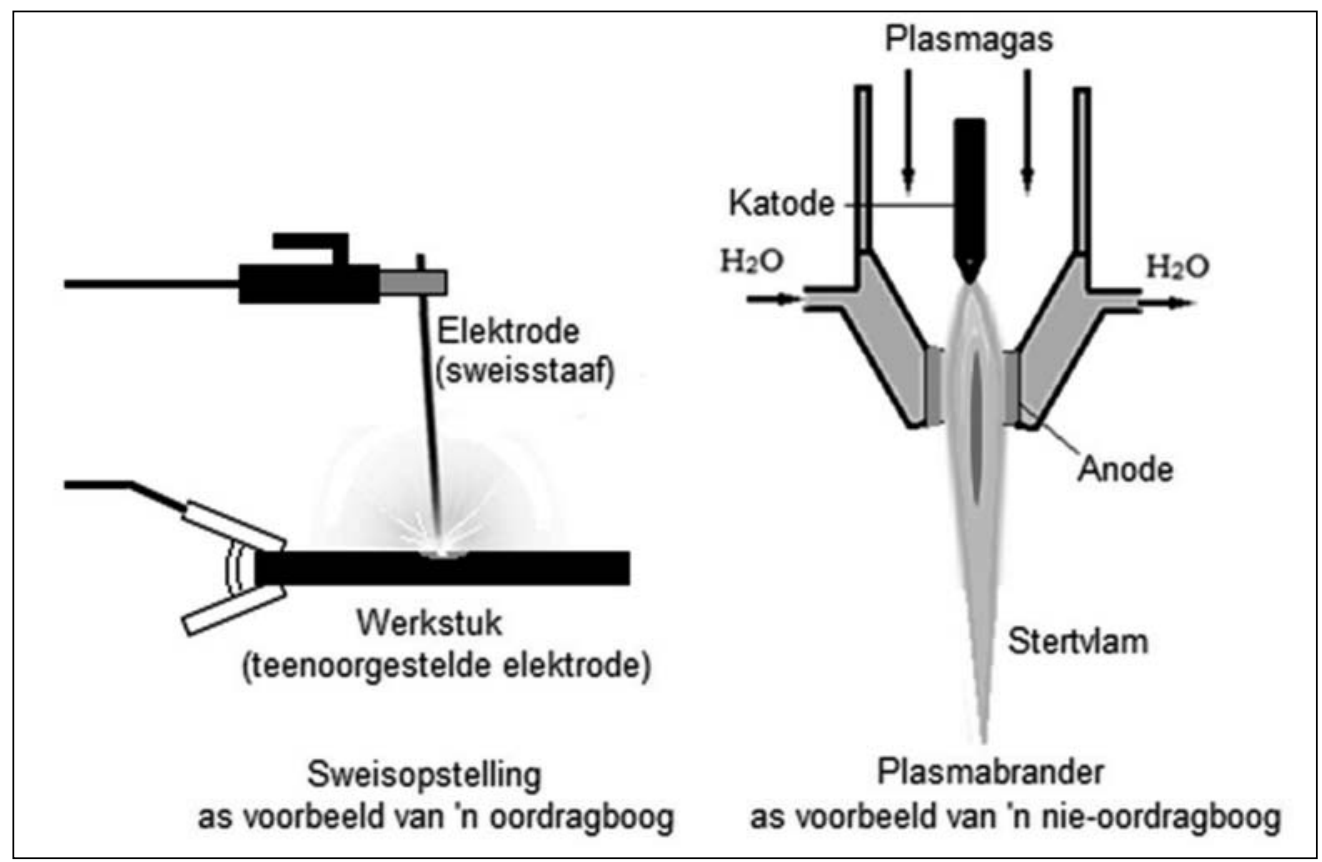

FIGUUR 4: Voorbeelde van ' $n$ oordragboog en 'n nie-oordragboogplasma 


\section{Nie-oordragboogplasmas}

In die geval van nie-oordragboogplasmas word die gas binne 'n doelgeskikte plasmabrander verhit en die stertvlam word vir aanwendings gebruik, soos vir die plasmabrander in Figuur 4 aangetoon. In die brander vloei die plasmagas en elektriese stroom tussen 'n katode en silindriese anode wat as uitlaat vir die verhitte gas dien. Die plasmagas word tangensiaal naby die katode in die brander ingelaat en die plasma-ontlading word deur die kombinasie van die gevormde gaswerwel en die koue wand gestabiliseer.

Elke plasmabrander het 'n spesifieke spanning/stroom verwantskap (VA-verwantskap) wat bepaal word deur die ontwerp en werk binne ' $n$ bepaalde bedryfsvenster van stroom, spanning en gasvloeitempo. Plasmadrywing word beheer deur die stroom te verander en die aangelegde spanning volg die VA-kurwe van die brander. Kragbronne is van die stroombeheer tipe en word ontwerp om by die brander se karakteristieke aan te pas.

Hoofsaaklik twee tipes katode nl. 'n hol (of "koue") tipe, of 'n soliede, (of "warm") tipe word gebruik.

Die sg. kouekatode bestaan uit 'n waterverkoelde putvormige koperbuis, met of sonder 'n elektromagneet daaromheen om erosie te beperk. Dit word veral gebruik in hoë-drywing toepassings (1 - 10 megawatt (MW)) en verskeie geometrieë kan gebruik word (Zhukov, 2007d).

Die sg. warmkatode bestaan uit ' $n$ waterverkoelde koperblok met 'n soliede metaalinsetsel. Toriumgedoteerde wol- fram word gewoonlik gebruik in die teenwoordigheid van inerte plasmagasse soos argon en stikstof. Wanneer die plasmagas suurstof bevat, kan sirkonium- of hafniumkatodes gebruik word. As alternatief word 'n waterverkoelde diafragma tussen die katode en anode aangebring en 'n inerte gas daar toegevoer om die katode teen oksidasie te beskerm, terwyl die plasmagas tussen die diafragma en anode toegevoer word. Warmkatodebranders kan gebruik word in toepassings van tot $1 \mathrm{MW}$ (Zhukov, 2007f).

Plasmabranders van tot $200 \mathrm{~kW}$, met grafietkatodes vir gebruik met 'n $\mathrm{CO}_{2} / \mathrm{CH}_{4}$ plasmagasmengsel, is al beskryf (Mostaghimi, 2015). Katode-erosie word beperk deur die neerslag van grafiet daarop vanweë die ontbinding van $\mathrm{CH}_{4}$.

Die anode bestaan uit 'n waterverkoelde buis wat verskillende geometrieë kan hê na gelang van die toepassing en die vereiste drywing (Zhukov, 2007c), (Camacho, 1988b). By die Gerdien-Lotz tipe plasmabranders (Figuur 5) word water deur gleuwe in die anodekanaal ingelaat en die plasma word gestabiliseer deur ' $n$ waterfilm wat verdamp om die plasmagas te vorm. Anders as by gasbranders waar die plasmagas naby die katode ingevoer word, vloei die stoom transversaal vanaf die anode-oppervlakte (Hrabovsky, 2009). Die anode-aanhegting is ekstern op 'n roterende skyf. Hierdie tipe plasmas word gekenmerk deur hul hoë massaspesifieke entalpie - bykans 'n ordegrootte meer as bv. in 'n lugplasma (Hrabovsky, 2011a).

Voorbeelde van 'n $45 \mathrm{~kW}(\mathrm{e})$ warmkatodeplasmabrander (Figuur 6), in bedryf teen $20 \mathrm{~kW}(\mathrm{e})(200 \mathrm{~V}, 100 \mathrm{~A})$ met 'n

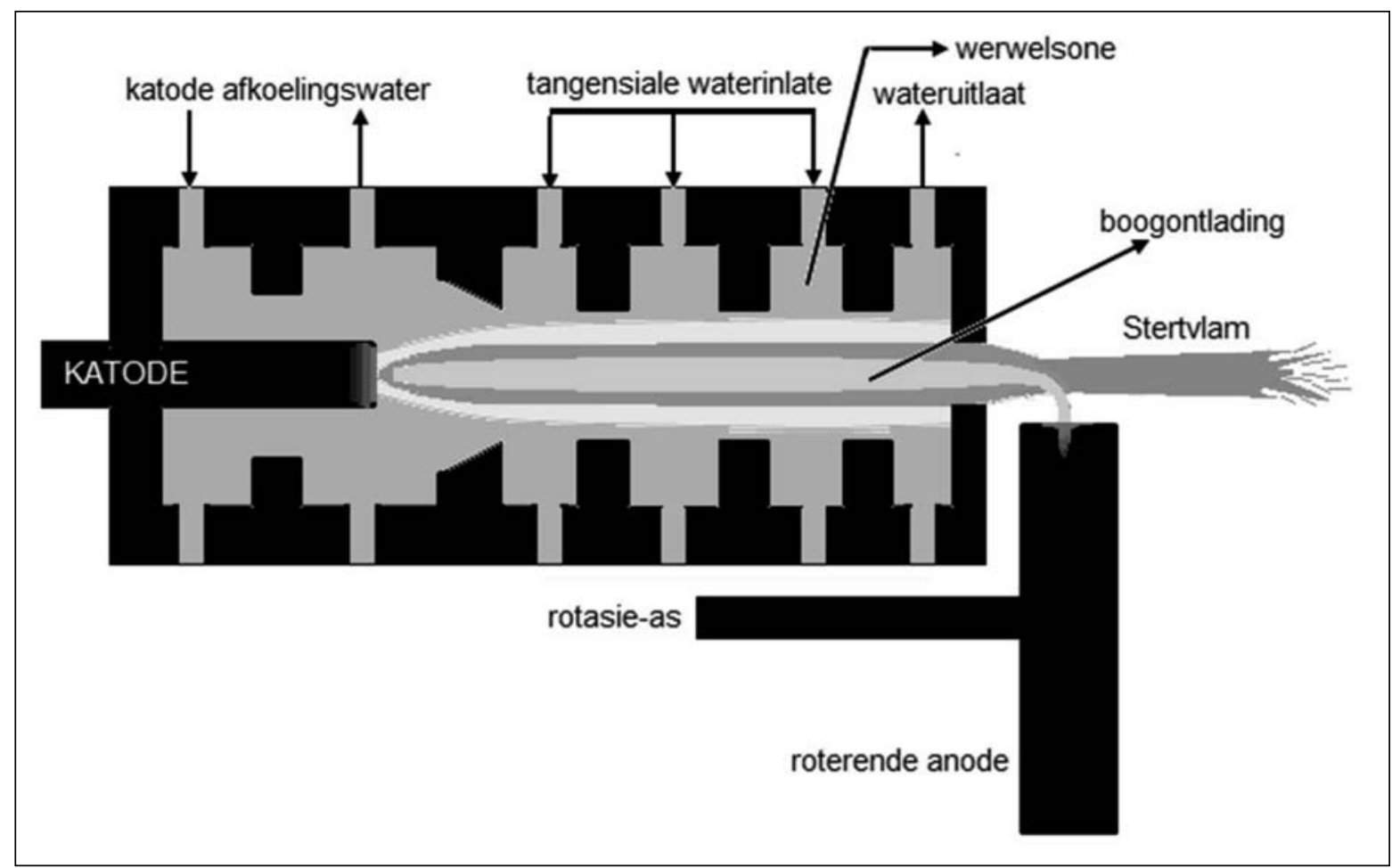

FIGUUR 5: Vloeistofgestabiliseerde plasmabrander (Hrabovsky, 2013). 


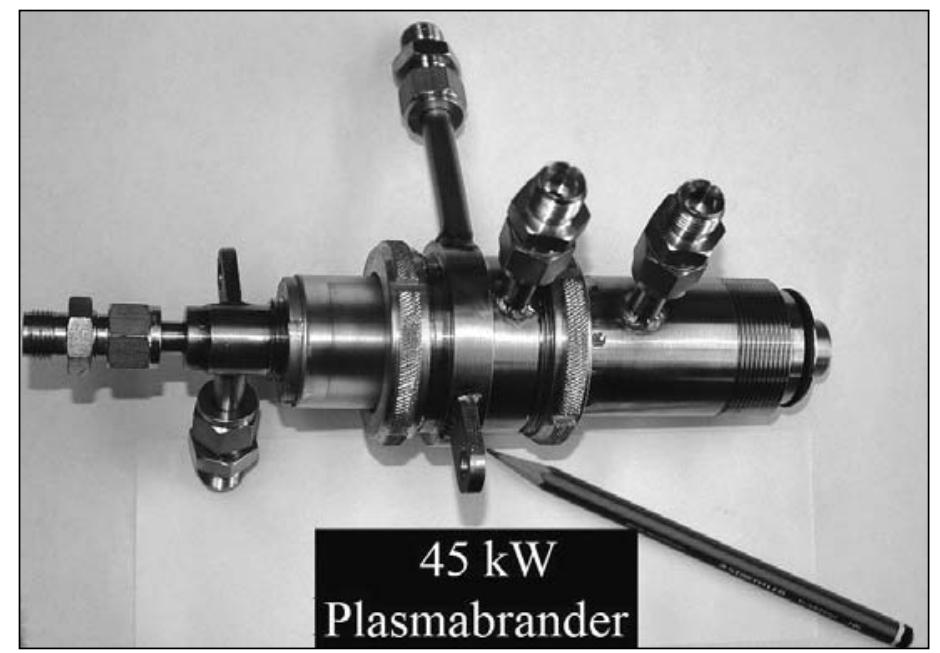

FIGUUR 6: $45 \mathrm{~kW}$ lug $/ \mathrm{N}_{2}$ plasmabrander.

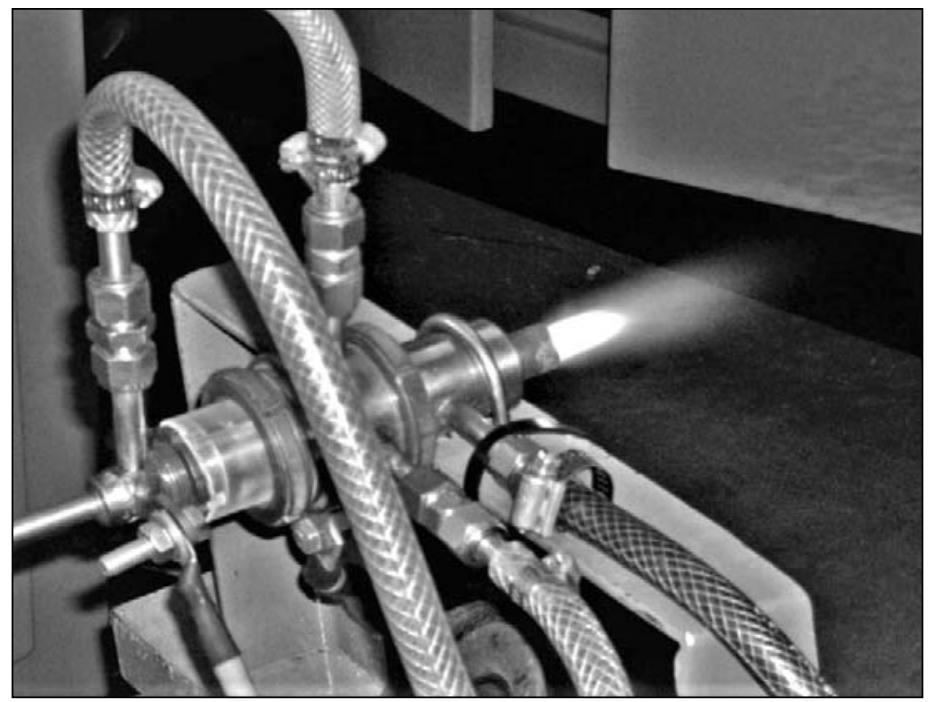

FIGUUR 7: $20 \mathrm{kW(e)} \mathrm{stikstofplasma.}$

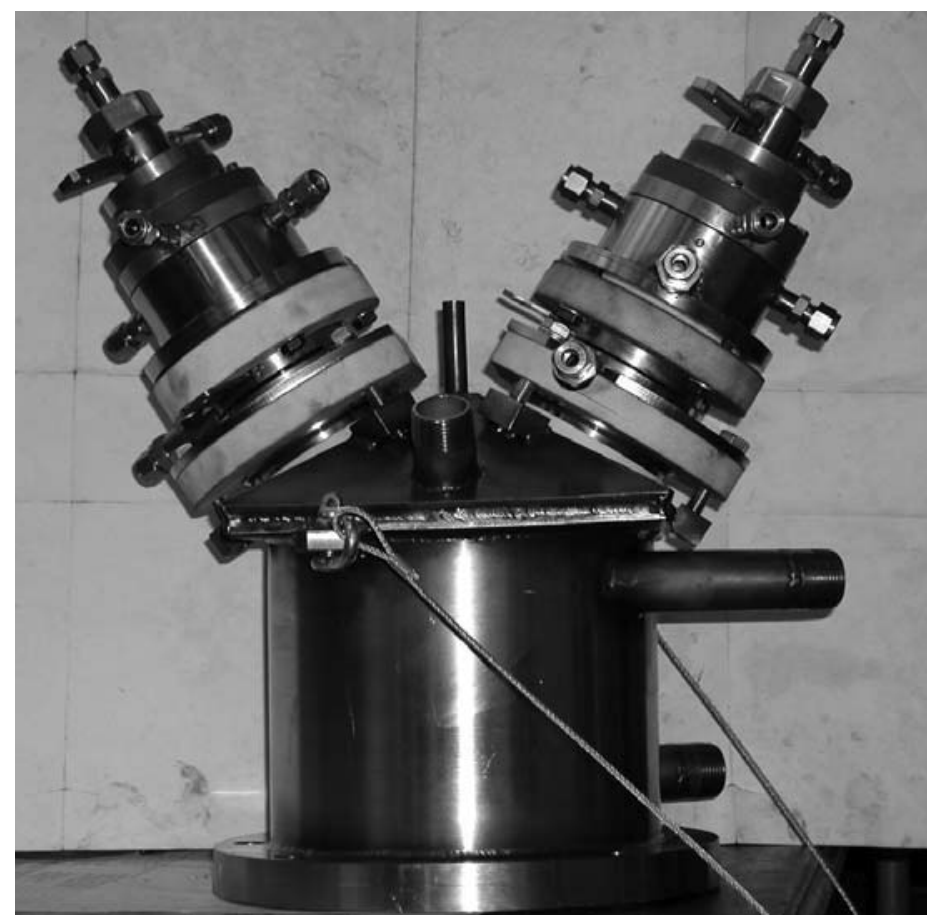

FIGUUR 8: V-vormige dubbelbrander opstelling. stikstofplasma (Figuur 7) en V-Tipe dubbelbranderopstelling (Figuur 8) word hieronder getoon. By laasgenoemde opstellings word twee branders in 'n V-vormige konfigurasie gebruik en word een brander as "katode" en die tweede as "anode" bedryf. Opstellings van tot $7 \mathrm{MW}$ is al in die nywerheid getoets (Zhukov, 2007g).

Elektrodeleeftye word bepaal deur 'n aantal faktore (Zhukov, 2007a), soos onder andere:

- Die keuse van plasmagas, elektrodemateriale en die versoenbaarheid tussen die twee;

- Die doeltreffende verkoeling van die elektrodes;

- Die diameter van die katode-insetsel en die stroomdigtheid, aangesien erosie toeneem met toename in stroomdigtheid. Wanneer die beperkende stroomdigtheid oorskry word, vorm bykomstige aanhegtingspunte;

- Die rotasietempo van die anode-aanhegtingspunt, deur die plasmagaswerwel of deur 'n eksterne magneetveld aan te bring in die omgewing van die aanhegtingspunt;

- Hoe dikwels die brander aan- en afgeskakel word.

\section{Nywerheidstoepassings van termiese plasmas}

Termiese boogontladingsplasmas word sedert die laat 19de eeu in die nywerheid gebruik vir nitraatvervaardiging, en wêreldwyd op groot skaal veral in pirometallurgiese prosesse, kontinue gietaanlegte, herwinning van skroot, en die sweis en sny van metale. Meer onlangse toepassings sluit in plasmasproei van metaal- en keramiekdeklae vir lugvaart-toepassings, sferoïdisering van metaal- en keramiekpoeiers, vervaardiging van nano-poeiers, skadeloosstelling van gevaarlike chemiese afval, en vitrifisering van die as uit munisipale-afvalverbranders, asbes en laevlak kernafval (Phoenix, 2019a), (Retech, 2019a).

Daar word ook wêreldwyd ondersoek ingestel na die herwinning van energie en nuttige produkte deur vergassing van koolstofhoudende materiaal soos munisipale- en plastiekafval, uitskotmotorbande en biomassa. Plasmas kan ook ingespan word by die voorbehandeling en ontsteking van steenkool in kragstasies (Blackburn, 1980), (Messerle, 2014), (Messerle, 2017,).

Plasma-enjins vir ruimtetuie is steeds ' $\mathrm{n}$ veld van aktiewe ondersoek (Dudeck, 2011), (AdAstra, 2015). 


\section{Suid-Afrikaanse ontwikkeling}

In Suid-Afrika word plasmanavorsing en -ontwikkeling hoofsaaklik by Mintek (SOE) en Necsa (SOC) gedoen. Mintek konsentreer op pirometallurgie en boogoonde en die Universiteite van Pretoria (UP, 2019), die Witwatersrand (WITS) en Stellenbosch (US, 2019) het pirometallurgienavorsingseenhede (Jones, 2018) terwyl Necsa se program op nie-oordragboog-, radiofrekwensie-, mikrogolf- en glimontlading plasmatoepassings toegespits is.

\section{Mintek}

Mintek het in 1934 ontstaan as 'n gesamentlike onderneming tussen die destydse Departement van Mynwese en die Universiteit van die Witwatersrand. Mintek doen ook internasionaal mee aan ontwikkelingswerk. Die leser word verwys na die werk van Curr (Curr, 2009) en Jones en Curr (Jones, 2006) vir meer volledige inligting as hieronder weergegee.

Meer as $50 \%$ van die chromieterts wat gemyn word, is fynmateriaal (sub-6 mm) wat nie geskik is vir prosessering in gesonke-boogoonde nie. Mintek en Middelburg Steel and Alloys het in 1979/80 suksesvolle loodsskaaltoetslopies begin gedoen met Tetronics oordragboogplasma-oonde . Die metallurgie is bewys, maar daar was egter probleme met elektrodeleeftye en die opskaal van plasmabranders na $>5$ MW. Rondom dieselfde tyd maak die beskikbaarheid van geskikte tiristors dit moontlik dat Stenqvist by ASEA 'n gelykstroom-oopboogoond kon ontwikkel, met 'n holgrafietkatode waardeur fyn materiaal na die oond toegevoer kon word.

Samewerking tussen Mintek en ASEA loop in 1984 uit op die ombouing van 'n bestaande wisselstroomoond by Palmiet Ferrochroom (nou Mogale Alloys) na 'n $12 \mathrm{MW}$ gelykstroomoond van die ASEA ontwerp, wat in 1988 opgradeer is na 28 MW. Intussen het Mintek in 1983 'n 1.2 MW gelykstroomoond gebou om hierdie werk te ondersteun. Die grootste van hierdie tipe oonde in SuidAfrika word bedryf deur Middelburg Ferrochrome, met 'n oond van $44 \mathrm{MW}$ en een van $60 \mathrm{MW}$ ontwerpkapasiteit (Sager, 2010).

Die smelt van ilmenieterts is in 1990 op loodsskaal by Mintek uitgevoer. Dit het gelei tot die bou van 'n $25 \mathrm{MW}$ gelykstroomoond by Namakwa Sands, en in 1998 'n 35 MW gelykstroomoond.

Staalsmelterstof word as skadelike afval beskou vanweë die swaarmetaalinhoud daarvan. Die Mintek "Enviroplas" stelsel (Schoukens, 1993) is ' $n$ gelykstroomboogproses om $\mathrm{Zn}, \mathrm{Ni}, \mathrm{Cr}$ en Mo daaruit te herwin. Zn word direk uit die afgas gekondenseer, terwyl $>90 \%$ van die res in die poel van gesmolte metaal agterbly. Die slak uit die proses is onskadelik en voldoen aan EPA standaarde vir wegdoening. Soortgelyke prosesse is deur Ausmelt en Tetronics ontwikkel (Street, 1998).

\section{Necsa}

Die destydse Uraanverrykingskorporasie (UKOR) het in die 1980's 'n plasma-N\&O-program met die oog op prosessering van uraanverbindings vir die kernbrandstofsiklus begin. Daar is ook getoon dat $\mathrm{Zr}$ metaal berei kan word deur reduksie van $\mathrm{ZrCl}_{4}$ in 'n waterstofplasma.

Met die beëindiging van die aanvanklike kernbrandstofprogram in die 1990's is die plasmaprogram met die oog op tegnolgiebehoud vir ander toepassings herbelyn (Van der Walt, 2015). Hieronder was programme vir:

- Die produksie (1994) van tetrafluoroetileen (TFE, $\mathrm{C}_{2} \mathrm{~F}_{4}$ ), die monomeer vir die vervaardiging van PTFE (Teflon ${ }^{\circledR}$ ) vanaf tetrafluorometaan $\left(\mathrm{CF}_{4}\right)$ en koolstof, wat tot op loodsaanlegskaal (450 kW plasma brander) ontwikkel is.

- Die vervaardiging van metaaloksiede $\left(\mathrm{ZrO}_{2^{\prime}}, \mathrm{TiO}_{2^{\prime}}\right.$ $\mathrm{SiO}_{2}$ ) en metaalkarbiede met plasmaprosesse. Natuurlike $\mathrm{ZrO}_{2}$ (baddeliet) kan vervang word met 'n alternatiewe bron van $\mathrm{ZrO}_{2}$ deur die chemies-inerte sirkoonmineraal $\left(\mathrm{ZrSiO}_{4}\right)$ in 'n plasma te dissosieer na $\mathrm{ZrO}_{2} \cdot \mathrm{SiO}_{2}$. Laasgenoemde staan bekend as plasmagedissosieerdesirkoon en is meer reaktief as sirkoon by gewone temperature (kamertemperatuur tot $\sim 150^{\circ} \mathrm{C}$ ) veral teenoor fluoorhoudende reagense soos $\mathrm{HF}$ en ammoniumbifluoried ( $\left.\mathrm{NH}_{4} \mathrm{~F} . \mathrm{HF}\right)$ (Havenga, 2011, Nel, 2011), (Makhofane, 2012). Plasmagedissosieerde sirkoon kan by gewone temperature droog, of in waterige medium met $\mathrm{HF}$ geprosesseer word om $\mathrm{ZrF}_{4}$ en, uiteindelik $\mathrm{ZrO}_{2}$, te herwin as basis vir 'n reeks sirkoniumprodukte. Die proses is ontwikkel tot semikommersiële skaal $(100 \mathrm{~kg} / \mathrm{h})$ met drie $150 \mathrm{~kW}$ nieoordragplasmabranders en is tussen 1995 en 2003 by Necsa bedryf. Daar is in beginsel getoon dat nano-silika $\left(\mathrm{SiO}_{2}\right)$ en $\mathrm{HF}$ herwin kan word deur die $\mathrm{SiF}_{4}$ afvalstroom van die droë proses met stoom in 'n plasmareaktor te behandel.

- Titaanoksiedpigment is in 'n plasmaproses geproduseer deur $\mathrm{TiCl}_{4}$ in-vlug met $\mathrm{O}_{2}$ te verhit $(\mathrm{Nel}, 2010)$.

- Kerngraadboorkarbied $\left(\mathrm{B}_{4} \mathrm{C}\right)$ nano-poeiers (80 - 100 $\mathrm{nm}$ ) is geproduseer deur die gasfasereaksie van $\mathrm{BCl}_{3}$ met metaan en waterstof in 'n termiese argonplasma.

- Sirkoniummetaal word tradisioneel met die Krollproses vervaardig deur die enkelladingreduksie van $\mathrm{ZrCl}_{4}$ met magnesium. Daar is op $30 \mathrm{~kW}$ skaal getoon dat $\mathrm{ZrCl}_{4}$ in vlug met $\mathrm{Mg}$ tot $\mathrm{Zr}$ gereduseer kan word in 'n plasmareaktor. Dit maak 'n kontinue proses in beginsel moontlik (Nel, 2012).

- Plasmasferoïdisering van titaan- en sirkoniumpoeiers is suksesvol in 'n termiese RF plasma gedoen om die poeiers te suiwer en vryvloeiend te maak vir nywerheidstoepassings (Bissett, 2015). Hiervoor is ' $n$ doelgemaakte RF-plasmastelsel aangekoop. 


\section{Nywerheidstoepassings in Suid-Afrika}

Pirometallurgie is verreweg die grootste toepassing van plasmas in Suid-Afrika. Op die hoogtepunt van die bedryf was daar 50 aanlegte (Jones, 2018) in Suid-Afrika soos opgesom in Tabel 2. Tans is daar ' $n$ hele aantal hiervan wat weens verskeie redes (mark- en kosteverwant) uit bedryf gestel of gesluit is.

\section{Afvalverwerking}

Die aanvaarde hiërargie vir afvalbebstuur in dalende prioriteit is: Vermy, verminder, herwin, hergebruik, gevolg deur energieherwinning en laastens, storting, met die langtermyndoelwit om laasgenoemde na nul af te bestuur.

Energie kan op verskeie maniere direk of indirek uit verbrandbare (organiese) afval herwin word, nl. verbranding, pirolise en vergassing. Pirolise en vergassing kan uitgevoer word as outotermiese of allotermiese prosesse. In outotermiese prosesse word die behoefte aan prosesenergie voorsien deur die gedeeltelike verbranding van die voermateriaal met suurstof of lug. By allotermiese prosesse word die energie verkry van 'n eksterne bron, bv. elektriese verhitting of 'n plasma.

\section{Verbranding}

Verbranding is die oudste en steeds mees algemene proses om bindingsenergie uit organiese materiaal vry te stel. Die afgasstroom bestaan hoofsaaklik uit $\mathrm{CO}_{2}$ en waterdamp en spore van onsuiwerhede ( $\mathrm{NO}_{x^{\prime}} \mathrm{SO}_{x^{\prime}} \mathrm{HCl}$, dioksiene, ens.) na gelang van die verbrandingstemperatuur en die samestelling van die voermateriaal.

\section{Pirolise}

Pirolise vind plaas in die afwesigheid van suurstof en lewer 'n komplekse reeks krakingsprodukte wat wissel van tere, vlugtige verbindings en gasse, tot koolstof, soos die temperatuur toeneem van ongeveer $200^{\circ} \mathrm{C}$ tot $900^{\circ} \mathrm{C}$. Die grootste nywerheidstoepassings van pirolise word gevind in die olieraffinering-, kooks- en houtskoolbedrywe.

\section{Vergassing}

Volgens R W Breault van die National Energy Technology Laboratory (NETL) in die VSA is vergassing meer doeltreffend as verbranding, die afgas is skoner en die kapitaalkoste is kompeterend (Breault, 2010). Vir beide tegnologieë is die kragopwekkingskoste bykans dieselfde, terwyl die hoër kapitaalkoste van vergassing verhaal word uit die hoër doeltreffendheid. Die vergassing van steenkool is wêreldwyd verreweg die grootste toepassing, bv. Sasol I en Sasol II plaaslik.

Vergassing van koolstofhoudende materiale word uitgevoer by temperature bo $900^{\circ} \mathrm{C}$ onder suurstofarm kondisies en lewer hoofsaaklik sintesegas met wisselende $\mathrm{CO}_{2}$ - en $\mathrm{H}_{2} \mathrm{O}$-inhoud. Die $\mathrm{CO}: \mathrm{H}_{2}$-verhouding in die gas word bepaal deur die voginhoud en elementsamestelling (tipies $\mathrm{C}, \mathrm{H}, \mathrm{O}, \mathrm{N}, \mathrm{S}$ ) van die voermateriaal en opsionele stoom- of suurstoftoevoer na gelang van die eindgebruik, hetsy chemiese sintese $\left(\mathrm{H}_{2}\right.$-ryk gas) of kragopwekking (CO-ryk gas). Tans is die vergassing van steenkool vir koolwaterstofproduksie en kragopwekking die grootste nywerheidstoepassing en die vergassing van biomassa en organiese afval 'n opkomende tegnologie.

Die belangrikste vergassingsreaksies word in Tabel 3 uiteengesit (NETL, 2019b).

As gevolg van die reduserende kondisies in die reaktor verskyn die S-inhoud in die voermateriaal hoofsaaklik as $\mathrm{H}_{2} \mathrm{~S}$ en $\mathrm{COS}$ in die afgas, en die $\mathrm{Cl}$ as $\mathrm{HCl}$ wat geskrop word om die sintesegas te suiwer vir verdere gebruik.

Hoofsaaklik vier vergasserkonfigurasies word kommersieel gebruik, nl. vastebed- (ook genoem bewegendebed)-, sleurvloei- transportvloei- en sweefbedvergassers (Breault, 2010), (NETL, 2019a) wat by hoë druk bedryf word. Voorbeelde van ' $n$ aantal van hierdie vergassers word ter illustrasie in Tabel 4 opgesom. Vir meer volledige inligting word die leser na die publikasie van Breault en die webwerf van die Amerikaanse National Energy Technology Laboratory (NETL), soos aangehaal, verwys.

TABEL 2: Opsomming van pirometallurgiese aanlegte in Suid-Afrika

\begin{tabular}{l|c|c|c}
\hline Produk & Aanlegte & Totale geïnstalleerde vermoë (geraam) & Totale geïnstalleerde kapasiteit \\
\hline Aluminium & 2 & Nie beskikbaar & $700 \mathrm{kt} / \mathrm{a}$ \\
& & & $175 \mathrm{kt} / \mathrm{a}$ (gesluit) \\
Ferrochroom & 14 & $2592(\mathrm{MVA})$ & $4240(\mathrm{kt} / \mathrm{a})$ \\
Ferromangaan & 4 & Nie beskikbaar & $900(\mathrm{kt} / \mathrm{a})$ \\
Ferrrosilikon & 3 & Nie beskikbaar & $28(\mathrm{kt} / \mathrm{a})$ \\
Ferrovanadium & 3 & Nie beskikbaar & 28.25 \\
Kalsiumkarbied & 1 & $52 \mathrm{MVA}$ & $100 \mathrm{kt} / \mathrm{a}$ \\
Platinumgroepmetale & 6 & $318(\mathrm{MVA})$ & $5.6 \mathrm{M} \mathrm{oz/a}$ \\
Silikon & 2 & $48 \mathrm{MVA}$ & $95 \mathrm{kt} / \mathrm{a}$ \\
& $\sim 60 \mathrm{MVA}$ & $55 \mathrm{kt} / \mathrm{a}$ gesluit \\
Siliko-mangaan & 3 & $193 \mathrm{MVA}$ & $435 \mathrm{kt} / \mathrm{a}$ \\
Titaanslak & 3 & $641 \mathrm{MVA}$ & $1528 \mathrm{kt} / \mathrm{a}$ \\
Vlekvrystaal & 1 & Nie beskikbar & Nie beskikbaar \\
Yster en staal & 6 & Nie beskikbaar & 8700 (kt/a) \\
\hline
\end{tabular}




\section{Plasmagesteunde vergassing}

Plasmagesteunde vergassing is ' $n$ hoëtemperatuurallotermiese proses waarin die organiese komponent van die voermateriaal volledig na sintesegas omgesit word.

Voordele van plasmavergassing, (Hrabovsky, 2011b), (NETL, 2019c), (AlterNRG) sluit in:

TABEL 3: Belangrikste vergassingsreaksies

\begin{tabular}{|c|c|c|c|}
\hline Verbrandingsreaksies & Reaksiewarmte & & \\
\hline \multirow[t]{2}{*}{$\mathrm{C}+1 / 2 \mathrm{O}_{2} \rightarrow \mathrm{CO}$} & $-9.25 \mathrm{MJ} / \mathrm{kg}$ & & \\
\hline & $-111 \mathrm{MJ} / \mathrm{kmol}$ & & [1] \\
\hline \multirow[t]{2}{*}{$\mathrm{CO}+1 / 2 \mathrm{O}_{2} \rightarrow \mathrm{CO}_{2}$} & $-10 \mathrm{MJ} / \mathrm{kg}$ & & \\
\hline & $-283 \mathrm{MJ} / \mathrm{kmol}$ & & [2] \\
\hline \multirow[t]{2}{*}{$\mathrm{H}_{2}+1 / 2 \mathrm{O}_{2} \rightarrow \mathrm{H}_{2} \mathrm{O}$} & $-121 \mathrm{MJ} / \mathrm{kg}$ & & \\
\hline & $-242 \mathrm{MJ} / \mathrm{kmol}$ & & [3] \\
\hline \multicolumn{4}{|l|}{ Heterogenefase reaksies } \\
\hline \multirow[t]{2}{*}{$\mathrm{C}+\mathrm{H}_{2} \mathrm{O} \leftrightarrow \mathrm{CO}+\mathrm{H}_{2}$} & $+10.9 \mathrm{MJ} / \mathrm{kg}$ & (Watergas reaksie) & {$[4]$} \\
\hline & + $131 \mathrm{MJ} / \mathrm{kmol}$ & & \\
\hline \multirow[t]{2}{*}{$\mathrm{C}+\mathrm{CO}_{2} \leftrightarrow 2 \mathrm{CO}$} & $+14.3 \mathrm{MJ} / \mathrm{kg}$ & (Boudouard reaksie) & [5] \\
\hline & + $172 \mathrm{MJ} / \mathrm{kmol}$ & & \\
\hline \multirow[t]{2}{*}{$\mathrm{C}+2 \mathrm{H}_{2} \leftrightarrow \mathrm{CH}_{4}$} & $-6.25 \mathrm{MJ} / \mathrm{kg}$ & (Metanering) & [6] \\
\hline & $-75 \mathrm{MJ} / \mathrm{kmol}$ & & \\
\hline \multicolumn{4}{|l|}{ Verskuiwingsreaksies } \\
\hline \multirow[t]{2}{*}{$\mathrm{CO}+\mathrm{H}_{2} \mathrm{O} \leftrightarrow \mathrm{CO}_{2}+\mathrm{H}_{2}$} & $-1.46 \mathrm{MJ} / \mathrm{kg}$ & (Water-gas-verskuiwing) & [7] \\
\hline & $-41 \mathrm{MJ} / \mathrm{kmol}$ & & \\
\hline \multirow[t]{2}{*}{$\mathrm{CH}_{4}+\mathrm{H}_{2} \mathrm{O} \leftrightarrow \mathrm{CO}_{2}+3 \mathrm{H}_{2}$} & $+12.9 \mathrm{MJ} / \mathrm{kg}$ & (Stoom-metaan-omvorming) & [8] \\
\hline & $+206 \mathrm{MJ} / \mathrm{kmol}$ & & \\
\hline
\end{tabular}

- Onafhanklike beheer oor energietoevoer en redokskondisies in die reaktor. Die samestelling en energieinhoud van die sintesegas kan dus na gelang van die eindgebruik deur die keuse van temperatuur, plasmagas en addisionele oksidant oor 'n wyer gebied beheer word as in die geval van outotermiese vergassing;

- Die hoë entalpie van die plasmagas wat hitte-oordrag na die proses baie doeltreffend maak;

- Die hoë entalpie van die plasmagas beteken dat relatief klein gasvloeie benodig word om steeds voldoende energie vir die vergassingsproses te verskaf, met die bykomstige voordeel dat gashanteringstelsels meer kompak word;

- Plooibaarheid t.o.v. voermateriaal, bv. steenkool, steenkoolpoeier, mynafval, biomassa, munisipale afval, ou motorbande, die as uit munisipale afvalverbranders en vloeistowwe van allerlei aard;

- Probleme wat met outotermiese vergassing ondervind word, soos bv. beperkte beheer oor die samestelling en kwaliteit van die sintesegas word uitgeskakel;

- Die vorming van tere en ander kondenseerbare produkte word uitgeskakel deur die hoë temperatuur;

- Meer doeltreffende omsetting van koolstof na die gasfase en laer $\mathrm{CO}_{2}$-emissies as in verbranders;

- Herwinning van die anorganiese komponent van die voermateriaal in die vorm van inerte slak, klinker of as na gelang van behoefte.

TABEL 4: Voorbeelde van kommersiële vergassers

\begin{tabular}{|c|c|c|c|}
\hline Tipe & Tegnologie/kenmerke & Voermateriaal & Oksidasiegas \\
\hline GE/Chevron Texaco & $\begin{array}{l}\text { Hoëdruk, enkelstadium, afwaartse sleurvloei, slakvormend, } \\
45 \text { jaar nywerheidsbedryf }\end{array}$ & Steenkoolflodder & $\mathrm{O}_{2}$ \\
\hline CB\&I E-gas (ConocoPhilips) & Hoëdruk, twee-stadium, opwaartse sleurvloei, slakvormend. & Steenkoolflodder & $\mathrm{O}_{2}$ \\
\hline Shell & Hoëdruk, enkelstadium, afwaartse sleurvloei, slakvormend. & Droë steenkool & $\mathrm{O}_{2} /$ stoom \\
\hline Siemens/Babcock Borsig & Hoëdruk, enkelstadium, sleurvloei, slakvormend. & Droë steenkool & $\mathrm{O}_{2}$ \\
\hline $\begin{array}{l}\text { Uhde-Prenflow } \\
\text { (ThyssenKrupp, 2019) }\end{array}$ & Hoëdruk, enkelstadium, afwaartse sleurvloei, slakvormend. & Droë steenkool/ petroleumkooks & $\mathrm{O}_{2}$ \\
\hline Siemens & Hoëdruk, sleurvloei, slakvormend & $\begin{array}{l}\text { Droë steenkool (antrasiet tot ligniet), } \\
\text { ook biomassa, petroleumkooks, afval olie. }\end{array}$ & $\mathrm{O}_{2}$ \\
\hline $\begin{array}{l}\text { Mitsubishi Heavy Industries } \\
\text { (MHI) }\end{array}$ & Hoëdruk, tweestadium, opwaartse sleurvloei, slakvormend & Droë laegraadse steenkool & Lug \\
\hline ECUST & Hoëdruk, hoëtemperatuur, afwaartse sleurvloei & $\begin{array}{l}\text { Steenkoolflodder. Droë steenkoolpoeier met } \\
\text { pneumatiese transport }\left(\mathrm{N}_{2} \text { of } \mathrm{CO}_{2}\right)\end{array}$ & Lug, $\mathrm{O}_{2}$ \\
\hline Lürgi & $\begin{array}{l}\text { Hoëdruk, bewegende bed, droë-as-vergasser, laetemperatuur } \\
\left(<1000^{\circ} \mathrm{C}\right) \text {, asvormend (SASOL) }\end{array}$ & Growwe steenkool & Stoom $/ \mathrm{O}_{2}$ \\
\hline British Gas Lürgi (BGL) & $\begin{array}{l}\text { Hoëtemperatuur, vaste/bewegende bed, slakvormende weergawe } \\
\text { van die Lürgi vergasser. }\end{array}$ & $\begin{array}{l}\text { Droë steenkool. Mengsels van hout/ bande/ } \\
\text { gesorteerde afval kan toegevoeg word. }\end{array}$ & Stoom $/ \mathrm{O}_{2}$ \\
\hline Kellogg, Brown en Root (KBR) & Tweestadium, hersirkulerende sweefbed, asvormend & $\begin{array}{l}\text { Droë, growwe laegraadse steenkool/ } \\
\text { kalksteen }\end{array}$ & $\begin{array}{l}\text { Stoom/lug of } \\
\text { stoom } / \mathrm{O}_{2}\end{array}$ \\
\hline U-Gas & Enkelstadiumsweefbed & $\begin{array}{l}\text { Droë steenkool, petroleumkooks, biomassa, } \\
\text { nywerheidsafval en kombinasies daarvan. }\end{array}$ & $\begin{array}{l}\text { Stoom/lug of } \\
\text { stoom } / \mathrm{O}_{2}\end{array}$ \\
\hline $\begin{array}{l}\text { Hoëtemperatuur Winkler } \\
\text { vergasser }\end{array}$ & Hoëdruk, hersirkulerende sweefbed, asvormend. & Droë steenkool, biomassa. & Lug of $\mathrm{O}_{2}$ \\
\hline
\end{tabular}




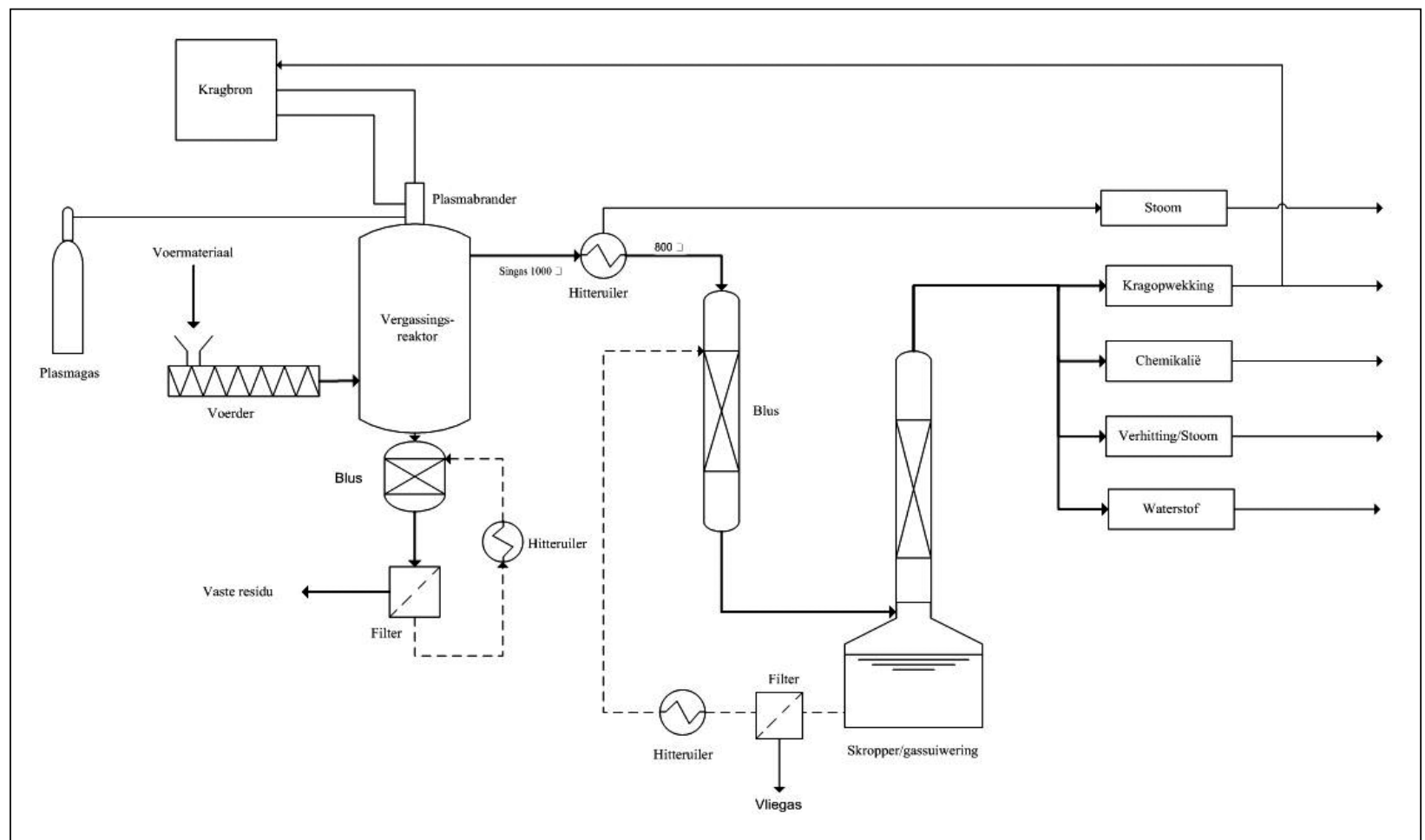

FIGUUR 9: Konseptuele skema vir 'n plasmavergassingstelsel.

Oor die algemeen word plasmavergassing by temperature bo $1000^{\circ} \mathrm{C}$ uitgevoer. Die warm produkgasstroom word geblus, bv. met water, om die hoëtemperatuursamestelling termodinamies te "vries", wat terselfdertyd ook meegesleurde vliegas verwyder. Die koue gasstroom word daarna verder gesuiwer deur 'n alkaliese skropproses om suurgaskomponente te verwyder.

Die reaktorkonfigurasie sal ' $\mathrm{n}$ rol speel in die vorming van kondenseerbare produkte en tere in die afgas, bv. by biomassavergassing, (Bain, 2004), (Lettner, 2007). Waar nodig kan die produkgasstroom gesuiwer word in 'n sekondêre plasmareaktor voor dit geblus word.

Die plasmavergassing van afval word tans nog nie op die skaal van konvensionele vergassing uitgevoer nie. Die grootste kommersiële projek dusver (Stockton-on-Tees) is gestaak voordat dit volle produksie bereik het (AirProducts, 2016) 'n Skematiese voorstelling van 'n plasmavergasserstelsel met moontlike eindgebruike word in Figuur 9 weergegee.

\section{Verskaffers van termiese-plasma- stelsels en toerusting}

'n Verkorte lys van gevestigde internasionale verskaffers van plasmatoerusting, -prosesse en -dienste word in Tabel 5 opgesom.

\section{Opsomming}

Vanweë die omvang van die aktiwiteite en vakliteratuur wat met plasmategnologie verband hou, is volledigheid haas onmoontlik. Hierdie oorsig poog om aan die nievakkundige leser ' $n$ aanduiding te gee van die ontstaangeskiedenis, aard en toepassings van plasmas in hul verskeie voorkomsvorme en om as beginpunt te dien vir verdere studie.

\section{Erkenning}

Die skrywers bedank die Suid-Afrikaanse Akademie vir Wetenskap en Kuns vir hul finansiële ondersteuning van die studies van AA Jansen. Necsa word bedank vir die toestemming om foto's van plasmatoerusting te gebruik. Dr G Nothnagel word bedank vir waardevolle insette t.o.v. die plasmatoestand.

\section{Mededingende belange}

Die skywers verklaar geen konflik van belange nie. Die skrywers het geen kommersiële belange by, en onderskryf ook nie, enige produkte of dienste van die plasmaveskaffers gelys in Tabel 5 nie - dit is bloot 'n opsomming van inligting vryelik op die internet beskikbaar. 
TABEL 5: Opsomming van verskaffers van plasmatoerusting, prosesse en dienste

\begin{tabular}{|c|c|c|}
\hline $\begin{array}{l}\text { Maatskappy } \\
\text { InEnTec }\end{array}$ & $\begin{array}{l}\text { Ligging / Webtuiste } \\
\text { Richland, WA, VSA, www.inentec.com }\end{array}$ & $\begin{array}{l}\text { Toerusting/Dienste } \\
\text { PEM (Plasma Enhanced Melter) afvalvergasser/vitrifiseerder. Stoom/suurstof } \\
\text { vergassing/vitrifisering van biomassa, munisipale- mediese-, industriële afval, } 60 \\
\text { tot } 300 \mathrm{~kg} / \mathrm{h}\end{array}$ \\
\hline B2B Global Solutions & $\begin{array}{l}\text { Margate, Florida USA } \\
\text { http://www.b2b-globalsolutions.com/ }\end{array}$ & $\begin{array}{l}\text { “Plasma Arc Gasification” (PAG) sisteem; stoomvergassing (10 kg } 150^{\circ} \mathrm{C} \text { stoom per } \\
\mathrm{kg} \text { afval). Voertempo } 4.5 \mathrm{~m}^{3} / \mathrm{h} / 270 \mathrm{~kg} / \mathrm{h}\end{array}$ \\
\hline PEAT International & $\begin{array}{l}\text { Northbrook IL, } \\
\text { VSA http://www.peat.com }\end{array}$ & $\begin{array}{l}\text { "Plasma Thermal Destruction and Recovery" (PTDR) proses. Primêre pirolise } \\
\text { dmv grafiet-boogontlading, sekondêre vergassing met stoom } / \mathrm{O}_{2} .100-3400 \\
\text { kW stelsels vir } 60 \text { tot } 1500 \mathrm{~kg} / \mathrm{h} \text { industriële, gevaarlike en mediese afval. Singas } \\
\text { kragopwekking ( } 450 \text { tot } 2000 \mathrm{~kW} \text { ) }\end{array}$ \\
\hline Phoenix Solutions Co (PSC) & $\begin{array}{l}\text { Minneapolis, MN, VSA } \\
\text { http://www.phoenixsolutionsco.com/ }\end{array}$ & $\begin{array}{l}\text { Oordragboog en nie-oordragboog branders van } 10 \text { tot } 3000 \mathrm{~kW} \text { vermoë. } \\
\text { Eie toetsfasiliteit in VSA. Plasma verhittingstelsels vir energie-uit-afval, } \\
\text { metallurgie, afvalremediëring nanopartikelproduksie, fotovoltaïese-graad silikon, } \\
\text { platinumgroep metaalherwinning. } \\
\text { Kliënte in Asië, VSA, Europa }\end{array}$ \\
\hline Retech Systems LLC & $\begin{array}{l}\text { Ukiah, CA, VSA } \\
\text { http://www.retechsystemsllc.com/ }\end{array}$ & $\begin{array}{l}\text { Plasmaboog smelter (“Plasma Arc Melter" (PAM)), Vakuum booghersmelt } \\
\text { (“Vacuum Arc Remelting” (VAR)), Elektronbundel (EB) smelter, Plasma sentrifugale } \\
\text { smelter/verbrander ("Plasma Arc Centrifugal Technology" (PACT)) vir gevaarlike } \\
\text { chemiese- en laevlak radio-aktiewe afval, (Zwilag, Muttenz, Switserland).Plasma } \\
\text { gietwerk, Oordragboog plasmabranders, laboratoriumskaal plasmastelsels }\end{array}$ \\
\hline Alter NRG Corp & $\begin{array}{l}\text { Calgary, Alberta, Kanada } \\
\text { http://www.alternrg.com/ }\end{array}$ & $\begin{array}{l}\text { Kommersiële energie-uit-afval aanlegte in Asië, Indië. Verskaf } 2 \times 1000 \text { tpd G65 } \\
\text { vergassers aan Air Products vir Teesside munisipale afvalverwerking projek, } \\
\text { intussen gestaak. }\end{array}$ \\
\hline $\begin{array}{l}\text { Westinghouse Plasma } \\
\text { Corporation }\end{array}$ & Madison, PA & $\begin{array}{l}\text { Vergassingstelsels, plasmabranders ( } 80-2400 \mathrm{~kW}) \text {. Tegnologie word bemark } \\
\text { deur Alter NRG Corporation }\end{array}$ \\
\hline Tetronics (International) Limited & $\begin{array}{l}\text { Swindon, VK } \\
\text { https://tetronics.com/ }\end{array}$ & $\begin{array}{l}\text { Reeds } 50 \text { jaar verskaffer van plasmategnologie ( } 127 \text { patente). } 90 \text { plasma } \\
\text { installasies op } 4 \text { kontinent en } 20 \text { jaar bedryfsgeskiedenis. Herwinning van nie- } \\
\text { ysterhoudende- en platinumgroepmetale, en prosessering van uitskot smeltkroes } \\
\text { belyning, e-afval, en gevaarlike chemiese afval }\end{array}$ \\
\hline Advanced Plasma Power (APP) & $\begin{array}{l}\text { Swindon, VK } \\
\text { https://advancedplasmapower.com/ }\end{array}$ & Vennootskap met Tetronics. Gasplasma: afval-na-energie proses. \\
\hline Europlasma Group & $\begin{array}{l}\text { Morcenx, Frankryk } \\
\text { http://www.europlasma.com/ }\end{array}$ & $\begin{array}{l}\text { Plasmabranders, prosesse, navorsing. Inertam: vitrifisering van afval (as, asbes, } \\
\text { sand, grond), LLW, MLW). CHO Power ( } 55000 \text { tpa,11 MWe) energie-uit- afval } \\
\text { proses (biomassa, munisipale afval). }\end{array}$ \\
\hline Scan-ArcPlasma Technologies AB & $\begin{array}{l}\text { Hofors, Swede } \\
\text { http://www.scanarc.se/en/ }\end{array}$ & $\begin{array}{l}\text { Bou en verskaf plasmabranders van } 100 \mathrm{~kW} \text { tot } 8 \mathrm{MW} \text { hoofsaaklik vir metallurgiese } \\
\text { toepassings. Plasma prosesse vir herwinning van metale uit industriële prosesafval, } \\
\text { vergassing van afval. }\end{array}$ \\
\hline PyrogenesisCanada Inc & Montreal, Quebec, Kanada & $\begin{array}{l}\text { Ontwerp, ontwikkel en kommersialiseer plasmaprosesse. Plasma Arc Waste } \\
\text { Destruction System (PAWDS) aan boord Carnival Cruise Lines skip. }\end{array}$ \\
\hline Tekna Plasma Systems Inc & $\begin{array}{l}\text { Sherbrooke, Quebec, Kanada } \\
\text { https://www.tekna.com/ }\end{array}$ & $\begin{array}{l}\text { Ontwikkel, vervaardig en verskaf radiofrekwensie induksieplasma branders } \\
\text { en kragbronne, volledige stelsels vir die sferoïdisering van metaal- en kera- } \\
\text { miekpoeiers, vervaardiging van nano-materiale, entalpiesondes, poeier voer- } \\
\text { stelsel, Verskaf gesegmenteerde nie-oordragboog plasma stelsels } 15 \mathrm{~kW} \text { tot } 1 \mathrm{MW} \\
\text { en plasmaboog tonnels (PAT) vir toets van hitteskerms van ruimtetuie. }\end{array}$ \\
\hline Plazarium & $\begin{array}{l}\text { Sierre, Switserland (HK); Berlyn; Moskou. } \\
\text { www.plazarium.com }\end{array}$ & $\begin{array}{l}\text { Navorsing en ontwikkeling. } \\
\text { Plasmabranders van } 30 \mathrm{~kW} \text { tot } 350 \mathrm{~kW} \text { en groter branders (tot } 2500 \mathrm{~kW} \text { ) op } \\
\text { aanvraag, } 100 \mathrm{~kW} \text { stoom branders } \\
\text { Plasmareaktore (PGR); volledige doelgemaakte stoom-vergassingstelsels (TPS); } \\
\text { mobiele vergassers (MGS); mobiele pirolisestelsels (MPS); mobiele brandstof } \\
\text { fraksioneringstelsels (MFS) } \\
\text { Kragbronne en beheerstelsels vir boog, mikrogolf en hibriedplasmabranders tot } \\
500 \mathrm{~kW}\end{array}$ \\
\hline $\begin{array}{l}\text { Utag Green Energy Technologies } \\
\text { Inc }\end{array}$ & $\begin{array}{l}\text { Toronto, Ontario, Kanada } \\
\text { http://www.utagtechnology.com/ }\end{array}$ & $\begin{array}{l}\text { Verskaf toerusting vir stoom-plasma vergassing van biomassa, steenkool, en } \\
\text { petroleumkooks. } 8 \text { MWTe biomassavergasser by Guessing, Oostenryk, sedert } 2001\end{array}$ \\
\hline $\begin{array}{l}\text { High Temperature Technologies } \\
\text { Corp (HTT) }\end{array}$ & $\begin{array}{l}\text { Chateugueay, Quebec, Kanada } \\
\text { http://www.httcanada.com/ }\end{array}$ & $\begin{array}{l}\text { Verskaf nie-oordragboog WS ( } 100-240 \mathrm{~kW}), \mathrm{GS}(50-500 \mathrm{~kW}) \text {, stoom (GS, } 100- \\
300 \mathrm{~kW} \text { ) branders. GS oordragboog branders }(60-300 \mathrm{~kW})) \text {. } \\
\text { Plasma oonde en volledige aanlegte vir die verwerking van munisipale afval, } \\
\text { biomassa, houtresidu, motorbande, plastiek, chemiese- en biomediese afval, } \\
\text { asbes, vliegas, flodder en laevlak radio-aktiewe afval (LLW). }\end{array}$ \\
\hline
\end{tabular}




\section{Outeursbydraes}

AAJ was verantwoordelik vir die konseptualisering, navorsing vir, en is hoofskrywer van hierdie oorsig. Hierdie artikel vorm deel van sy doktorale studie.

PLC tree op as akademiese studieleier.

IJvdW tree op as mede-studieleier en borg van die projek.

\section{Verwysings}

Adastra. 2015 Space propulsion: Our engine [Aanlyn]. Ad Astra Rocket Company. Beskikbaar: http://www.adastrarocket.com/aarc/VASIMR [Toegang Beskikbaar:

Airproducts. 2016. Air products will exit Energy-from Waste Business [Aanlyn] Beskikbaar: http://www.airproducts.co.uk/Company/news-center/2016/04/ 0404-air-products-will-exit-energy-from-waste-business.aspx [Toegang 20191002].

Alternrg. Waste to Energy [Aanlyn]. AlterNRG Corp. Beskikbaar: www.alternrg.com/ waste_to_energy/ [Toegang 20191004].

Artsimovich LA. Controlled fusion research in the USSR. Second United Nations International Conference on the peaceful uses of atomic energy, 1 September-13 September 19581958 Geneva. United Nations, 6-20.

Aschwanden M. 2004. Physics of the solar corona_an introduction, Springer Science \& Business Media.

Bain RL. 2004. An Introduction to Biomass Thermochemical Conversion [Aanlyn]. U S National Renewable Energy Laboratory (NREL). Beskikbaar: https://www. nrel.gov/docs/gen/fy04/36831e.pdf [Toegang 20190927 2019].

Barbalace K. 2019. Periodic Table of Elements - Sorted by 1st Ionization Potential (eV) [Aanlyn]. EnvironmentalChemistry.com. 1995 - 2019. Beskikbaar: https:// EnvironmentalChemistry.com/yogi/periodic/1stionization.html [Toegang 20191008].

Barcza NA. 1986. The development of large scale plasma systems. Journal of the Southern African Institute of Minining and Metallurgy, 86, 321, 329.

Basov N, Krokhin O, Sklizkov GV. 1972. Heating of laser plasmas for thermonuclear fusion". In: SCHWARZ, H. J., HORA, H. (ed.) Laser Interaction and Related Plasma Phenomena. Boston MA: Springer.

Berthelot M. 1860. Synthèse de l'acétylène par la combinaison directe du carbon avec l'hydrogène. Comptes rendus hebdomadaires des séances de l'Académie des sciences, 3, 640-644.

Bissett H, Van der Walt IJ, Havenga JL, Nel JT. 2015. Titanium and zirconium metal spheroidization by thermal plasma processes. J Southern African Inst Min Metall, 115, 937-942.

Blackburn P. 1980. Ignition of pulverized coal with arc heated air. Journal of Energy, 4, 98-99.

Boulos MI. 1985. The inductively coupled RF (radiofrequency) plasma. Pure \& App/ Chem, 57, 1321-1352

Boulos MI. 2004. Plasma power can make better powders. Metal Powder Report, $59,16-21$.

Boulos MI, Fauchais P, Pfender E. 1994a. The Plasma State. Thermal Plasmas. Fundamentals and Applications. New York and London: Plenum Press. bl 8.

Boulos MI, Fauchais P, Pfender E. 1994b. The Plasma State. Thermal Plasmas. Fundamentals and Applications. New York and London Plenum Press, bl 9-10.

Boulos MI, Fauchais P, Pfender E. 1994c. Thermal Plasmas. Fundamentals and Applications, New York, Plenum Press.

Brandenburg R. 2017. Dielectric barrier discharges: progress on plasma sources and on the understanding of regimes and single filaments. Plasma Sources Science and Technology, 26

Breault RW. 2010. Gasification Processe Old and New: A Basic Review of the Major Technologies. Energies, 3, 216-240.

Brittanica E. 2019. Arc lamp [Aanlyn]. Encyclopedia Brittanica. Beskikbaar: https:// www.brittanica.co/technology/arrc-lamp [Toegang 20191002].

Burgess MPD. 2011. Semiconductor Research and Developmnet at General Electric [Aanlyn]. Beskikbaar: https://sites.google.com/site/transistorhistory/Home/ us-semiconductor-manufacturers/general-electric-history [Toegang]

Camacho SL. 1987. The reverse polarity plasma torch. ISPC-8. Tokyo.

Camacho SL. 1988a. Industrial-worthy plasma torches: State-of-the-art. Pure \& Appl Chem, 60, 619-632.

Camacho SL. 1988b. Industrial-worthy plasma torches: State-of-the-art. Pure \& Appl Chem, 60, 619-632.
Caron M, Héroult P. (1863 v 1914): un grand inventeur original. La Vie des Sciences, Comptes Rendus, Serie Generale, 5, 39-57.

Clarycon.com. 2019. Capacitive and Inductive Coupling [Aanlyn]. Clarycon. Beskikbaar: www.clarycon.com/plasmacoupling2.html [Toegang 20191003].

Cormier JM, Aubry O, Khacef A. 2007. Degradation of Organic Compounds and Production of Activated Species in Barrier Discharges and Glidarc Reactors, Springer.

Crouse PL. 1993. The effect of deposition parameters on the compressive stress in a-C: $\mathrm{H}$ thin films. Diamond and Related Materials, 2, 885-889.

Curr TR. 2009. The history of DC arc furnace development" Voordrag,. Mintek 75. Randburg.

De Cew GG. 1882. Magneto- and Dynamo-Electric Machines, London, Symons and Co.

Doremus GC. 1907. Pierre Eugéne Marcellin Berthelot. Science, new series, 25, 593.

Dudeck F, Doveil F, Arcis N, Zurbach S. 2011. Plasma Propulsion for Geostationary Satellites and Interplanetary Propulsion. Romanian Journal of Physics 56, 3-14.

Dyer PE, Snelling HV. 2013. Gaslasers for medical applications. Lasers for Medical Applications, Diagnostics, Therapy and Surgery Woodhead Publishing.

Ebnessajjad S, Ebnesajjad C. 2016. Surface treatment of fluoropolymers for adhesion, in Surface Treatment of Materials for Adhesive Bonding. Elsevier. bl 113-124.

Eliasson B, Kogelschatz U. 1988. ÜV excimer radiation from dielectric barrier discharges. Applied Physics B, 46, 299.

Fabry F, Rehmet C, Rohani V-J, Fulcheri L, Springer, Dordrecht, Netherlands. 2013. Waste gasification by thermal Plasma: A Review. Waste and Biomass Valorization, 421-439.

Fauchais PL, Boulos MI, Pfender E. 1987. Physical and thermodynamic properties of thermal plasmas. In: Feinman J. (ed.) Plasma Technology in Metallurgical Processing. Warrendale, PA: The Iron and Steel Society, Inc.

Fauchias PL, Heberlein, J, Boulos MI. 2014. RF induction plasma spraying. Thermal Spray Fundamentals - from powder to part. Boston, MA: Springer.

Feinman J. 1987a. Introduction. In: Feinman J. (ed.) Plasma Technology in Metallurgical Processing Warrendale, PA: The Iron and Steel Society Inc.

Feinman J. 1987b. Plasma Technology in Metallurgical Processing, Warrendale PA, Kuhn LG.

Gage RM. 1957. Arc Torch and Process. USA patent application.

Gerdien H, Lotz A. 1922. Wiss. Veroffentlichungen Siemenswerk, 2.

Gerdien H, Lotz A. 1923. Zeitschrift für Technische Physik. 4, 157.

Havenga JL, Nel JT. 2011. The manufacture of plasma-dissociated zircon (PDZ) via a non-transferred arc process utilizing three $150 \mathrm{~kW}$ DC plasma torches. The Journal of the Southern African Institute of Mining and Metallurgy, 112, 497500 .

Heberlein J, Mentel J, Pfender E. 2009. The anode region of electric arcs: a survey. Journal of Physics D: Applied Physics, 43.

Heberlein J, Murphy AB. 2008. Thermal plasma waste treatment. Journals of Physics D: Applied Physics, 41.

Heller A. 2019. On the threshold of a critical milestone. Lawrence Livermore National Laboratory.

Holtman C, Klaka S, Rahimo M, Moglestue A. 2019. Semiconductor generations. Abb looks back on 60 years of progress in semiconductors. In: BOVERI, A. B. (ed.) ABB Review.

Hrabovsky M. 2009. Thermal plasma generators with water-stabilized arc. The Open Plasma Physics Journal, 2, 99-104.

Hrabovsky M. 2011a. Steam plasma flows generated in Gerdien Arc: Environment for energy gas production from organics and for seurface coatings. Journal of Fluid Science and Technology, 6, 792-801.

Hrabovsky M. 2011b. Thermal plasma gasification of biomass. Progress in Biomass and Bioenergy Production. Intechopen.

Hrabovsky M. 2013. DC torches with arc b stabilization by liquids. In: Matvee I. (ed.) Plasma Assisted Combustion, Gasification, and Pollution Control, Vol 1Methods of Plasma Generation for PAC. Denver, CO: Outskirts Press Inc.

Jones RT. DC arc furnaces - past, present and future. In: Mackey J, Grimsey EJ, Jones RT, Brookw GA, ed. Celebrating the megascale: proceedings of the extraction
and processing division symposium on pyrometallurgy in honor of David GC and processing division symposium on pyrometallurgy in honor
Robertson, 2014. The Minerals, Metals and Materials Society, 2.

Jone RT. 2018. Pyrometallurgy in Southern Africa [Aanlyn]. Pyro.co.za. Beskikbaar: https://www.pyrometallurgy.co.za/PyroSA [Toegang 20191004] 
Jones RT, Curr TR. 2006. Pyrometallurgy at Mintek. In: Jones RT. (ed.) Southern African Pyrometallurgy 2006. Johannesburg: South African Institute of Mining and Metallurgy.

Kersten H. 2019. History of Gas Discharge Physics [Aanlyn]. Universiteit Kiel. Beskikbaar: https://www.ieap.uni-kiel.de/plasma/ag-kersten/en/history-gasdischarge-physics [Toegang 20191007 2019].

Kopecki J, Schultz A, Walker M, Glatz-Reichenbach J, Peter K, Stroth U. 2008. Plasma spraying technique for the deposition of $\alpha-\mathrm{Si} / \mu \mathrm{c}-\mathrm{Si}$. IEEE Transactions on spraying technique for the
Plasma Science, 36, 982-983.

Langmuir I. 1928. Oscillations in ionized gases. Proceedings of the National Academy of Sciences of the United States of America, 14, 627-637.

Langmuir I, Blodgett KB. 1924. Currents limited by space charge between concentric spheres. Physics Reviews, 24

Leins $M$, Kopecki J, Gaiser S, Schultz A, Walker M, Schumacher U, Stroth U, Hirth T. 2013. Microwave plasmas at atmospheric pressure. Contributions to Plasma Physiscs, 54, 14-26.

Lettner F, Timmerer H, Haselbacher P, (Intelligent Energy Europe). 2007. Deliverable 8: biomass gasification - State of the art description. Guideline for safe and eco-friendly biomass gasification. Graz University of Technology - Institute of Thermal Engineering, Inffeldgasse 25B, $8010 \mathrm{Graz}$, Austria.

Maecker H. 1956. Plasma streams produced by self-magnetic compression and its importance for the mechanism of high current arcs. Applied Scientific importance for the mechanism
Research, Section $A, 5,231-236$.

Makhofane MM, Havenga JL, Nel JT, Du Plessis W, Pretorius CJ. 2012. Manufacturing of anhydrous zirconium tetrafluoride in a batch reactor from plasmadissociated zircon and ammonium bifluoride. I Southern African Inst Min Metall, 112, 559-562.

Maslan F. Process for thermal fixation of atmospheric nitrogen. The Space Congress Proceedings, 1969. Embry-Riddle Aeronautical University.

Mendehall CE, Eve AS, Keys DA, Sutton RM. 1956. College Physics, Boston D C Heath and Company.

Messerle AV, Messerle VE, Ustimenko AB. 2017. Plasma thermochemical preparation for the combustion of pulverized coal. High Temperature, 55 352-360.

Messerle VE, Karpenko El, Ustimenko AB. 2014. Plasma assisted power coal combustionthe furnace of utility boiler: Numerical modelling and full-scale test. Fuel, 126, 294-300.

Moissan MHS. 1897. Le Four Électrique In: PARIS, B. D. S. C. D. (ed.) Paris: gallica.bnf. fr/Université Paris Sud.

Mostaghimi J, Boulos MI. 2015. Thermal plasma sources: how well are they adopted to process needs? Plasma Chemistry and Plasma Processing, 35, 421-436.

Murphy AB, Verpřek S. 2014. In gratitude to Steven Girschick. Plasma Chemistry and Plasma Processing, 34, 703-704.

Deutches Museam. 2019. The development of electric power [Aanlyn]. Deutches Museum. Beskikbaar: https://www.deutsches-museum.de/en/exhibitions/ materials-energy/electric-power/history/ [Toegang 20191007].

Nature.com. 2019. Laser-produced Plasmas [Aanlyn]. Springer Nature Limited. Beskikbaar: https://www.nature.com/subjects/laser-produced-plasmas [Toegang 20191003].

Nel JT, Du Plessis W, Nhlabathi TN, Pretorius CJ, Jansen AA, Crouse PL. 2011. Reaction kinetics of the microwave enhanced digestion of zircon with ammonium acid fluoride. Journal of Fluorine Chemistry, 132, 258-262.

Nel JT, Havenga JL, Makhofane MM, Jansen AA. 2012. The plasma-assisted manufacture of zirconium metal powder from zirconium tetrafluoride. Journa of the Southern African Institute of Mining and Metallurgy, 112, 63-68.

Nel JT, Havenga JL, Swanepoel J, Bosman H. 2010. The plasma manufacturing of of titania pigment and nanotitania in a pilot plant. Journal of the Southern African Institute of Mining and Metallurgy, 110, 235-239.

Netl. 2019a. Commercial Gasfiers [Aanlyn]. National Energy Technology Laboratory. Beskikbaar: https://www.netl.doe.gov/research/Coal/energy-systems/ gasification/gasifipedia/types-gasifiers [Toegang 20191004 2019].

Netl. 2019b. Detailed Gasification Chemistry [Aanlyn]. National Energy Technology Laboratory (Netl). Beskikbaar: https://www.netl.doe.gov/research/coal/ energy-systems/gasification/gasifipedia/gasification-chemistry [Toegang 20191004 2019].

Netl. 2019c. Plasma Gasification [Aanlyn]. USA: National Energy Technology Laboratory (Netl). Beskikbaar: https://netl.doe.gov/research/Coal/energysystems/gasification/gasifipedia/westinghouse [Toegang 20190920].

Okumura T. 2010. Inductively coupled plasma sources and applications. Physics Research International.

Oxford References. 2018. Birkeland-Eyde process [Aanlyn]. Oxford Reference. Beskikbaar: http://www.oxfordreference.com/view/10.1093/oi/authority. 20110803095508165 (Toegang 20181101) [Toegang 20191002]
Page L, Adams NI. 1958. Principles of Electricity. An Intermediate Text in Electricity and Magnetism, Princeton NJ, D van Nostrand Company, Inc. .

Phoenix. 2019a. Nanoparticle generation [Aanlyn]. Phoenix Solutions Co. Beskikbaar: http://www.phoenixsolutionsco.com/nanoparticlegeneration. html [Toegang 20190812].

Phoeniex. 2019b. Waste Processing [Aanlyn]. Phoenix Solutions Co. Beskikbaar: http://www.phoenixsolutionsco.com/waste.html [Toegang 20191004].

Reid KJ, Camacho SL. 1987. Historical Review. In: FEINMAN, J. (ed.) Plasma Technology in Metallurgical Processing. Warrendale, PA: American Iron and Steel Society Inc.

Reiman AH, Fisch NJ. 2018. Suppression of tearing Modes by Radiofrequency Current Condensation. Physical Review Letters, 121.

Retech. 2019a. Legacy technologies [Aanlyn]. Retech Systems LLC. Beskikbaar: http://www.retechsystemsllc.com/legacy/ [Toegang 20191004].

Retech. 2019b. Vacuum Arc Remelt [Aanlyn]. Retech Systems LLC. Beskikbaar: www.retechsystemsllc.com/vacuum-arc-remelt. [Toegang 20190911].

Reynolds QG, Jones RT. 2004. Semi-empirical modelling of the electrical behaviour of DC-arc smelting furnaces. The Journal of The South African Institute of Mining and Metallurgy, 345-351.

Reynolds QG, Jones RT, Reddy BD. 2010. Mathematical and computational modelling of the dynamic behaviour of direct current plasma arcs. The Journa of The Southern African Institute of Mining and Metallurgy, 110, 733-742.

Sager D, Grant D, Stadle R, Schreiter T. 2010. Low cost ferroalloy extraction in DC-arc furnace at Middleburg Ferrochrome. The Journal of The Southern African Institute of Mining and Metallurgy, 110, 717-724.

Saha M. 1920. Ionization in the solar chromosphere. Philosophical Magazine. Reeks $6,40,472-488$.

Scanarc. 2016. History of the Company and development of plasma based metallurgical processes [Aanlyn]. ScanArc Plasma Technologies AB. Beskikbaar: http://www.scanarc.se/en/history/ [Toegang 20191003]

Schoukens AFS, Shaw F, Chemaly EC. 1993. The Enviroplas process for the treatment of steel-plant dusts. Journal of the South African Institute of Mining and Metallurgy, 93, 1-7.

Smith DR, Nordberg M. 2014. Spark Source Mass Spectrometry. In: Nordberg G, Fowler B, Nordberg M (ed.) Handbook on the Toxicology of Metals. 4de uitgawe: Elsevier/Academic Press.

Spitzer L. 1958. The Stellarator Concept. Physics of Fluids, 1, 253-264.

Stansfield A. 1907. The electric furnace. Its evolution, theory and practice, New York and London, Hill Publishing Company.

Street S, Brookes G, Reilly L, Worner HK. 1998. Environment and other bath smelting processes for treating organic and ferrous waste. Journal of Metals, 59, 43-47.

Tekna. 2019a. Teksphero Sheroidization Sysytems [Aanlyn]. Tekna. Beskikbaar: www.tekna.com/spheroidization-systems. [Toegang 20191001].

Tekna. 2019b. Thermal Spray [Aanlyn]. Tekna. Beskikbaare: http://www.tekna.com/ applications/thermal-spray [Toegang 20191003].

Tetronics. 2019. Hazardous Waste Treatment Solutions [Aanlyn]. Tetronics International. Beskikbaar: https://tetronics.com/assets/Hazardous-WasteBrochure1.pdf [Toegang 20191004].

Thakur SN, Singh JP. 2007. Fundamentals of laser induced breakdown spectroscopy. Laser Induced Breakdown Spectroscopy. Elsevier.

Thyssenkrupp. 2019. Prenflow and HTW [Aanlyn]. ThyssenKrupp. Beskikbaar: https://www.thyssenkrupp-industrial-solutions.com/en/products-andhttps://www.thyssenkrupp-industrial-solutions.com/en/products-and-
services/chemical-plants-and-processes/gasification/prenflo-and-htwtm [Toegang 20191004].

Ttrusov BG. 2006. Phase and chemical equilibrium in multiphase systems. 4.5e ed. Moscow: Baumann State University.

UP. 2019. Centre for Pyrometallurgy [Aanlyn]. Universiteit van Pretoria Beskikbaar: https://www.up.ac.za/materials-science-and-metallurgical-engineering/ article/48836/centre-for-pyrometallurgy [Toegang 20191001].

US. 2019. Extractive metallurgy [Aanlyn]. Stellenbosch: University of Stellenbosch Beskikbaar: http://www0.sun.ac.za/pgstudies/postgraduate-programmes/ faculty-of-engineering/department-of-process-engineering.html [Toegang 20191004 2019].

Van der Watl I.J, Nel JT, Crouse PL, Jansen AA, Kekana SJ. 2011. The treatment of TRISO coated particles with CF4 in a low temperature plasma. Journal of Nuclear Materials, 413, 156-161.

Van der Walt IJ, Nel JT, Havenga JL. 2015. Plasma Technology for the Manufacture of Nuclear materials at Necsa. Journal of the Southern African Institute of Mining and Metallurgy, 115, 943-948.

Weltmann K-D, Metelmann H-R, Von Woedtke TH. 2016. Low temperature plasma applications in medicine. Europhysicsnews, 47, 39-42. 
Wits. Research Entities in the School_Pyrometallurgy [Aanlyn]. University of the Witwatersrand. Beskikbaar: https://www.wits.ac.za/chemmet/research/ research-entities/ [Toegang 20191001].

WNN. 2018. Plasma plant starts operations in Bulgaria [Aanlyn]. World Nuclear News,. Beskikbaar: www.world-nuclear-news.org/WR-Plasma-plant-startsoperations-in-Bulgaria-10071801.html [Toegang 20191004].

Wolf R, Sparavigna AC. 2010. Role of plasma surface treatments on wetting and adhesion. Engineering, 2, 397-402.

Zhukov MF, Zasypkin IM. 2007a. Near electrode processes and methods of reducing electrode erosion. In: Zhukov M, Zasypkin IM. (ed.) Thermal Plasma Torches. Design, Characteristics, Applications. Cambridge UK: Cambridge International Science Publishing Ltd. bl 431.

Zhukov MF, Zasypkin IM. 2007b. Thermal Plasma Torches, Design, Characteristics, Applcations. Cambridge, UK, Cambridge International Science Publishing Ltd.

Zhukov MF, Zasypkin IM. 2007c. Brief Description of Plasma and Electric Heating of Gas. In: Zhukov MF, Zasypkin IM. (ed.) Thermal Plasma Torches. Design Characteristics, Application. Cambridge, UK: Cambridge International Science Publishing Ltd. bl 319-322
Zhukov MF, Zasypkin IM. 2007d. Brief description of thermal plasma and heating of gas. In: Zhukov MF, Zasypkin IM. (ed.) Thermal Plasma Torches. Design, Characteristics, Applications. Cambridge, UK: Cambridge International Science Publishing Ltd. bl 323-349

Zhukov MF, Zasypkin IM. 2007e. Direct current linear plasma torches. In: Zhukov MF, Zazypkin IM. (ed.) Thermal Plasma Torches. Design, Characteristics, Applications. Cambridge, UK: Cambridge International Science Publishing Ltd. bl 319 - 322.

Zhukov MF, Zasypkin IM. 2007f. Direct current linear plasma torches. In: Zhukov MF, Zasypkin IM. (ed.) Thermal Plasma Torches. Design, Characteristics, Zasypkin IM. (ed.) Thermal Plasma Torches. Design, Characteristics, Application
bl 328.

Zhukov MF, Zasypkin IM. 2007g. Two-jet plasma torches. In: Zhukov MF, Zasypkin IM. (ed.) Thermal Plasma Torches. Design, Characteristics, Applications. Cambridge, UK: Cambridge International Science Publishing Ltd. bl 350.

Zwilag. 2019. Installation and operational processes [Aanlyn]. Zwilag Zwischenlager Würenlingen AG. Beskikbaar: https://www.zwilag.ch/upload/cms/user/ Prospekt_Anlagen_Prozesse_E.PDF [Toegang 20191004]. 